\title{
Protein Kinase A-Mediated Suppression of the Slow Afterhyperpolarizing KCa3.1 Current in Temporal Lobe Epilepsy
}

\author{
Manindra Nath Tiwari, ${ }^{*}$ Sandesh Mohan, ${ }^{*}$ Yoav Biala, and $\odot$ Yoel Yaari \\ Department of Medical Neurobiology, Institute for Medical Research Israel-Canada, The Hebrew University-Hadassah School of Medicine, Jerusalem \\ 91120, Israel
}

Brain insults, such as trauma, stroke, anoxia, and status epilepticus (SE), cause multiple changes in synaptic function and intrinsic properties of surviving neurons that may lead to the development of epilepsy. Experimentally, a single SE episode, induced by the convulsant pilocarpine, initiates the development of an epileptic condition resembling human temporal lobe epilepsy (TLE). Principal hippocampal neurons from such epileptic animals display enhanced spike output in response to excitatory stimuli compared with neurons from nonepileptic animals. This enhanced firing is negatively related to the size of the slow afterhyperpolarization (sAHP), which is reduced in the epileptic neurons. The SAHP is an intrinsic neuronal negative feedback mechanism consisting normally of two partially overlapping components produced by disparate mechanisms. One component is generated by activation of $\mathrm{Ca}^{2+}-$ gated $\mathrm{K}^{+}\left(\mathrm{K}_{\mathrm{Ca}}\right)$ channels, likely KCa3.1, consequent to spike $\mathrm{Ca}^{2+}$ influx (the $\mathrm{K}_{\mathrm{Ca}}$-sAHP component). The second component is generated by enhancement of the electrogenic $\mathrm{Na}^{+} / \mathrm{K}^{+}$ATPase (NKA) by spike $\mathrm{Na}^{+}$influx (NKA-sAHP component). Here we show that the $\mathrm{K}_{\mathrm{Ca}}$-sAHP component is markedly reduced in male rat epileptic neurons, whereas the NKA-sAHP component is not altered. The $\mathrm{K}_{\mathrm{Ca}}$-sAHP reduction is due to the downregulation of KCa3.1 channels, mediated by cAMP-dependent protein kinase A (PKA). This sustained effect can be acutely reversed by applying PKA inhibitors, leading also to normalization of the spike output of epileptic neurons. We propose that the novel "acquired channelopathy" described here, namely, PKA-mediated downregulation of KCa3.1 activity, provides an innovative target for developing new treatments for TLE, hopefully overcoming the pharmacoresistance to traditional drugs.

Key words: acquired epilepsy; hippocampus; $\mathrm{KCa} 3.1 ; \mathrm{Na} / \mathrm{K}$ ATPase; protein kinase A; slow afterhyperpolarization

Significance Statement

Epilepsy, a common neurological disorder, often develops following a brain insult. Identifying key molecular and cellular mechanisms underlying acquired epilepsy is critical for developing effective antiepileptic therapies. In an experimental model of acquired epilepsy, we show that principal hippocampal neurons become intrinsically hyperexcitable. This alteration is due predominantly to the downregulation of a ubiquitous class of potassium ion channels, $\mathrm{KCa} 3.1$, whose main function is to dampen neuronal excitability. KCa3.1 downregulation is mediated by the cAMP-dependent protein kinase A (PKA) signaling pathway. Most importantly, it can be acutely reversed by PKA inhibitors, leading to recovery of KCa3.1 function and normalization of neuronal excitability. The discovery of this novel epileptogenic mechanism hopefully will facilitate the development of more efficient pharmacotherapy for acquired epilepsy.

\section{Introduction}

Temporal lobe epilepsy (TLE) is the most common form of adult epilepsy (Téllez-Zenteno and Hernández-Ronquillo, 2012). It is

\section{Received July 6, 2019; revised Sept. 24, 2019; accepted 0ct. 7, 2019.}

Author contributions: M.N.T. and Y.Y. designed research;M.N.T., S.M., and Y.Y. performed research; M.N.T., S.M.,

Y.B., and Y.Y. analyzed data; Y.Y. wrote the first draft of the paper. M.N.T. and S.M. and Y.Y. edited the paper.

This work was supported by the Israeli Science Foundation and the Deutsch-Israelische Projectkooperation program of the Deutsche Forschungsgemeinschaft.

*M.N.T. and S.M. share equal authorship.

Correspondence should be addressed to Yoel Yaari at yoely@ekmd.huji.ac.il. often instigated by a brain insult, which triggers a cascade of pathological alterations, termed epileptogenesis, leading to the establishment of brain hyperexcitability and the emergence of spontaneous seizures (Becker, 2018). Seizures commonly arise in the hippocampus and/or related mesiotemporal structures (Spencer and Spencer, 1994). Approximately 20-30\% of TLE patients become refractory to existing antiepileptic medication,

https://doi.org/10.1523/JNEUROSCl.1603-19.2019

Copyright $\odot 2019$ the authors 
Table 1. Comparisons between non-SE and post-SE rats with respect to membrane properties of CA1 pyramidal cells

\begin{tabular}{|c|c|c|c|c|c|c|c|c|c|c|}
\hline & \multicolumn{5}{|c|}{ Acute-phase neurons } & \multicolumn{5}{|c|}{ Chronic-phase neurons } \\
\hline & Non-SE $(n=6)$ & Post-SE $(n=9)$ & $t$ Value & df & $p$ Value & Non-SE $(n=21)$ & Post-SE $(n=21)$ & $t$ Value & df & $p$ Value \\
\hline Resting $V_{m}(m V)$ & $-74.7 \pm 1.2$ & $-72.0 \pm 0.97$ & 1.8 & 13 & 0.10 & $-73.4 \pm 0.7$ & $-71.5 \pm 1.0$ & 1.6 & 40 & 0.14 \\
\hline Input resistance ( $\mathrm{M} \Omega$ ) & $69.5 \pm 6.9$ & $69.4 \pm 8.7$ & 0.01 & 13 & 1.0 & $80.5 \pm 3.6$ & $93.8 \pm 5.6$ & 2.0 & 40 & 0.05 \\
\hline Spike amplitude (mV) & $83.8 \pm 2.7$ & $80.6 \pm 1.2$ & 1.2 & 13 & 0.24 & $86.8 \pm 1.1$ & $84.7 \pm 1.1$ & 1.4 & 40 & 0.19 \\
\hline Rheobase current (nA) & $0.83 \pm 0.1$ & $1.0 \pm 0.2$ & 0.9 & 13 & 0.40 & $0.96 \pm 0.1$ & $1.0 \pm 0.1$ & 0.3 & 40 & 0.78 \\
\hline
\end{tabular}

No significant differences were found in either acute-phase or chronic-phase animal subgroups.

thus presenting an almost untreatable medical condition (Kwan et al., 2011).

An epileptic condition resembling human TLE can be produced in rodents by a single episode of chemically induced status epilepticus (SE; Raol and Brooks-Kayal, 2012). A plethora of alterations in plasma membrane ion channels, synaptic transmission, gap-junctional coupling, and glial cell function were documented in post-SE hippocampal tissue (Pitkänen et al., 2015; Becker, 2018). Some of these alterations enhance hippocampal excitability, whereas others may serve a compensatory inhibitory function.

Pyramidal cells in hippocampal tissue obtained from post-SE, chronically epileptic rats, generate considerably more spikes in response to a given depolarization than neurons in non-SE tissue (Tamir et al., 2017). A key factor contributing to this enhanced spike output is a decrease in size of the slow afterhyperpolarization (sAHP; Tamir et al., 2017), an intrinsic neuronal negative feedback mechanism that mediates spike frequency accommodation in many types of neurons (Madison and Nicoll, 1984; Ha and Cheong, 2017). In pyramidal cells maintained in nearphysiological conditions, the sAHP is composed of two partially overlapping components (Gulledge et al., 2013; Tiwari et al., 2018). One component arises from the activation of $\mathrm{Ca}^{2+}$-gated $\mathrm{K}^{+}\left(\mathrm{K}_{\mathrm{Ca}}\right)$ channels by spike $\mathrm{Ca}^{2+}$ influx $\left(\mathrm{K}_{\mathrm{Ca}}\right.$-sAHP component). The $\mathrm{K}_{\mathrm{Ca}}$ channels generating $\mathrm{K}_{\mathrm{Ca}}$-sAHP have been recently identified as $\mathrm{KCa} 3.1$, the intermediate conductance $\mathrm{K}_{\mathrm{Ca}}$ channels (King et al., 2015; Turner et al., 2016; Sahu et al., 2017). The second component results from augmented activation of the $\mathrm{Na}^{+} / \mathrm{K}^{+}$ATPase [NKA (or $\mathrm{Na}^{+}$pump)] by spike $\mathrm{Na}^{+}$influx (NKA-sAHP component). The two components are subjected to differential regulation. For example, the activation of the cAMPdependent protein kinase A (PKA) inhibits $\mathrm{K}_{\mathrm{Ca}}$-sAHP (Madison and Nicoll, 1986; Pedarzani and Storm, 1993; Haug and Storm, 2000), but fails to modify the NKA-sAHP (Mohan et al., 2019). In contrast, endogenous "cardiotonic" steroids suppress NKAsAHP activity without directly affecting the $\mathrm{K}_{\mathrm{Ca}}$-sAHP (Gulledge et al., 2013; Tiwari et al., 2018). Given the key role of the sAHP in determining intrinsic neuronal excitability, it is important to explore which of its two components is modified in epileptic tissue and characterize the underlying mechanisms.

Here we have investigated the latter issue using the established rat pilocarpine-SE model of TLE (Turski et al., 1983; Sanabria et al., 2001). We report that the NKA-sAHP component in CA1 pyramidal cells remains unchanged even 5-6 weeks post-SE, whereas the $\mathrm{K}_{\mathrm{Ca}}$-sAHP component is strongly downregulated due to the dysfunction of KCa3.1 channels. We also show that this newly discovered "acquired channelopathy" contributes to the intrinsic hyperexcitability in post-SE neurons, and therefore may contribute to seizure generation in TLE.

\section{Materials and Methods}

Animal groups. Experimental protocols were approved by the local Animal Care and Use Committee. Wistar male rats (150-175 g) were used.
Male rats were preferred because they are more than fivefold more prone than female rats to develop SE following pilocarpine injection (Scharfman and MacLusky, 2014), which is a prerequisite for developing chronic epilepsy (Turski et al., 1983; Sanabria et al., 2001). Rats were injected intraperitoneally with a single dose of pilocarpine (300-380 $\mathrm{mg} / \mathrm{kg}$ ), inducing SE in $\sim 80 \%$ of the animals. Peripheral muscarinic effects were reduced by prior administration of methyl-scopolamine ( 1 $\mathrm{mg} / \mathrm{kg}$, s.c.). Diazepam $(0.1 \mathrm{mg} / \mathrm{kg}$, i.p. $)$ was administered to seizing rats $2 \mathrm{~h}$ after pilocarpine injection, terminating convulsions. The $24 \mathrm{~h}$ mortality rate of the latter animals was $\sim 10 \%$. Rats surviving the pilocarpineinduced SE constituted the post-SE group $(n=66)$. Rats receiving the same drug treatment protocol, but without pilocarpine, constituted the non-SE group $(n=35)$. Each group comprised two subgroups: acutephase rats were killed $2 \mathrm{~d}$ after drug treatment; chronic-phase rats were killed 5-6 weeks later.

Preparation of hippocampal slices. Rats were decapitated under isoflurane anesthesia, and transverse dorsal hippocampal slices $(400 \mu \mathrm{m})$ were prepared with a vibratome and transferred to a storage chamber perfused with oxygenated $\left(95 \% \mathrm{O}_{2}\right.$ and $\left.5 \% \mathrm{CO}_{2}\right)$ standard artificial CSF (aCSF) at room temperature. For recording, slices were placed one at a time in an interface chamber and superfused with warmed $\left(35.0^{\circ} \mathrm{C}\right)$ oxygenated standard aCSF containing additional drugs, as indicated.

Solutions. The standard aCSF comprised the following (in $\mathrm{mm}$ ): 124 $\mathrm{NaCl}, 3.5 \mathrm{KCl}, 1 \mathrm{MgCl}_{2}, 1.6 \mathrm{CaCl}_{2}, 26 \mathrm{NaHCO}_{3}$, and 10 glucose, $\mathrm{pH}$ 7.35; osmolarity $305 \mathrm{mOsm}$. All aCSFs used for recordings also contained 15 $\mu \mathrm{M}$ 6-cyano-7-nitroquinoxaline-2,3-dione (CNQX), $50 \mu \mathrm{M}$ aminophosphonovalerate (APV), $100 \mu \mathrm{M}$ picrotoxin, and $1 \mu \mathrm{M}$ CGP55845 to block excitatory and inhibitory synaptic transmission; and $20 \mu \mathrm{M}$ ZD7288 to block HCN channels. The aCSF designed to block voltage-gated $\mathrm{Ca}^{2+}$ channels also contained $\mathrm{NiCl}_{2}(200 \mu \mathrm{M})$ and $\mathrm{CdCl}_{2}(200 \mu \mathrm{M})$. The aCSFs used for recording $\mathrm{Ca}^{2+}$ spikes or $\mathrm{Ca}^{2+}$-dependent potentials and currents contained $0.5 \mu \mathrm{M}$ tetrodotoxin, $5 \mathrm{~mm} 4$-aminopyridine, $10 \mu \mathrm{M}$ XE991 (a blocker of $\mathrm{K}_{\mathrm{V}}$ 7/M channels), and $100 \mathrm{nM}$ apamin (a blocker of small conductance $\mathrm{K}_{\mathrm{Ca}}$ channels).

Electrophysiology. Intracellular recordings were obtained using sharp glass microelectrodes containing $4 \mathrm{M} \mathrm{K}^{+}$-acetate $(90-110 \mathrm{M} \Omega$ ) and a bridge amplifier (Axoclamp 2B, Molecular Devices) allowing switching between current-clamp and discontinuous voltage-clamp recordings (switching frequency between current injection and voltage sampling, $6-8 \mathrm{kHz}$ ). Signals were filtered on line at $1.5 \mathrm{kHz}$, digitized at a sampling rate of $\geq 10 \mathrm{kHz}$, and stored by a personal computer using a data acquisition system (Digidata 1322A) and pCLAMP9 software (Molecular Devices).

The pyramidal cells included in this study had a stable resting membrane potential $\left(V_{\mathrm{m}}\right)$ of at least $-60 \mathrm{mV}$ and an overshooting action potential. In standard aCSF, resting $V_{\mathrm{m}}$ values were similar across the four rat subgroups, as were input resistance, spike threshold current (rheobase current), and spike amplitude (Table 1). To reduce variations in spike output and in sAHP amplitudes across the pyramidal cells due to differences in resting $V_{\mathrm{m}}$ (Tiwari et al., 2018), all recordings were made from a "resting" $V_{\mathrm{m}}$ of $-70 \mathrm{mV}$ maintained by constant current injection.

Chemicals. Picrotoxin, CGP55845, $\mathrm{NiCl}_{2}, \mathrm{CdCl}_{2}$, TRAM34, pilocarpine, Rp-Adenosine 3',5' -cyclic monophosphorothioate triethylammonium (RPcAMP), scopolamine, and ouabain were obtained from Sigma-Aldrich; CNQX and APV from Alomone Labs; ZD7288 from Toc- 
A

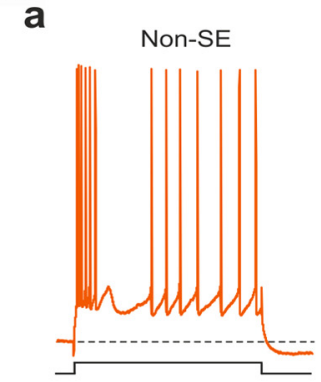

b

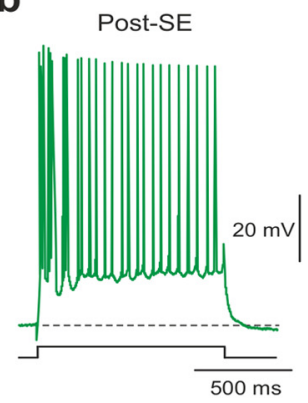

B

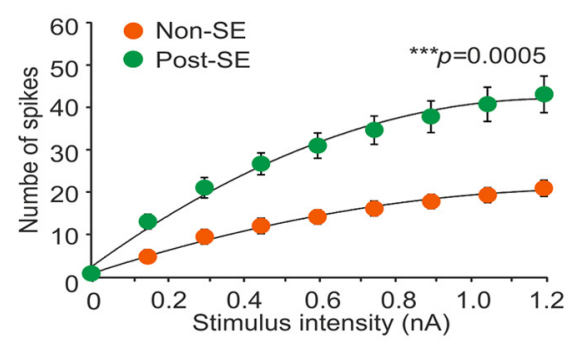

b

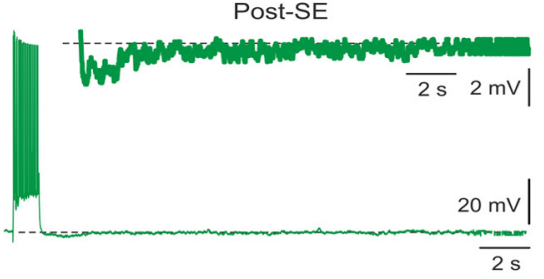

b

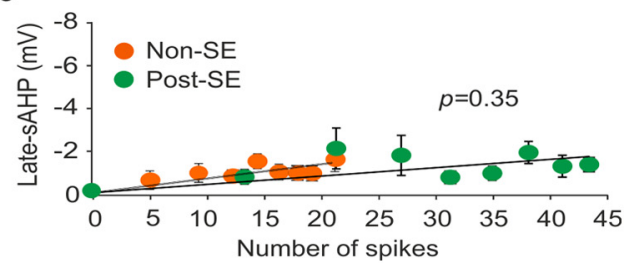

Figure 1. Spike outputs and sAHPs evoked by depolarizing current pulses in acute- and chronic-phase non-SE and post-SE neurons. A, Spikes were evoked in chronic-phase CA1 pyramidal cells by 1-s-long depolarizing current pulses from a resting $V_{m}$ of $-70 \mathrm{mV}$ (dashed line). $\boldsymbol{a}, \boldsymbol{b}$, Representative recordings of spike responses to $0.3 \mathrm{nA}$ stimuli are shown for a non-SE (a) and a post-SE neuron $(\boldsymbol{b}) \cdot \boldsymbol{B}$, Plots of the number of spikes versus stimulus intensity for the two subgroups of chronic-phase neurons. Note the significant increase in spike output of post-SE neurons compared with non-SE neurons. $\boldsymbol{C} \boldsymbol{a}, \boldsymbol{b}$, Representative recordings of sAHPs evoked by $0.3 \mathrm{nA}$ stimuli are shown for a non-SE $(\boldsymbol{a})$ and a post-SE neuron $(\boldsymbol{b})$. In each panel, the insets depict the sAHP in an enlarged format. Time points of amplitude measurements are indicated by arrows in Ca. Da, Summary plots of early sAHP amplitudes (measured at time point $1 \mathrm{~s}$ after the stimulus) versus the number of spikes evoked by the stimuli for the two subgroups of chronic-phase neurons. Db. Same as in $\boldsymbol{a}$, but for late sAHP amplitudes (measured at time point $7 \mathrm{~s}$ after the stimulus). Note the significant decrease in early sAHP amplitudes in the post-SE neurons.

ris Bioscience; and H89 from Abcam-Zotal. Drugs were diluted 1:1000 when added to the aCSF from stock solutions.

Data analysis. The experimenter was not blind to the animal condition, because brains of chronic-phase post-SE rats, when compared with non-SE rats, often look shrunken, the cell density in the pyramidal layer is reduced, evoked field potentials manifest multiple spiking, and spike ADPs are larger (Sanabria et al., 2001). Statistical analyses were performed using SPSS, QuickCalcs, and MS Excel. Statistical tests included paired and unpaired (two-tail) Student's $t$ test, Mann-Whitney test (unpaired comparisons), and Wilcoxon signed rank test (paired comparisons). Plots of number of spikes (Ns) versus stimulus intensity ( $I$; in nA) were fitted with a second-order polynomial regression equation: $f(y)=$ $b_{2} x^{2}+b_{1} x+b_{0}$. The initial slope of the regression line (parameter $b_{1}$ ) provided the slope (referred to as "firing response gain") of the relationship (Tamir et al., 2017). Plots of sAHP amplitudes versus the number of spikes were fitted with the following linear regression equation: $f(y)=a x$ $+b(a)$, the slope of the regression line. Summary data are presented as the mean \pm SEM from $n$ rats or neurons. Statistical significance in each case is denoted as follows: ${ }^{\star} p<0.05,{ }^{* *} p \leq 0.01$, and ${ }^{* * *} p \leq 0.001$. The values of the $t$ statistic and the $\mathrm{df}$ were added to all comparisons using the Student's $t$ test.

\section{Results}

Electrophysiological recordings were made in CA1 pyramidal cells in slices obtained from 66 rats that experienced pilocarpineinduced SE (post-SE) and 35 rats that did not (non-SE). Each of these two animal groups comprised the following two subgroups: acute-phase rats ( $n=8$ post-SE and $n=8$ non-SE rats), which were killed $2 \mathrm{~d}$ after conditioning drug treatment; and chronicphase rats ( $n=58$ post-SE and 27 non-SE rats), which were killed 5-6 weeks later (see Materials and Methods). Each rat provided no more than two slices for experimental recordings. Depending on the type of experiment, each slice provided data from one or two neurons.

The chronic-phase rats in both non-SE and post-SE groups were approximately two times heavier than acute-phase rats. However, no significant differences in animal weights were found between acute-phase non-SE $(203.4 \pm 1.6 \mathrm{~g} ; n=8)$ and post-SE (194.6 \pm 14.6 g; $n=8$ ) subgroups (unpaired Student's $t$ test: $t=$ $0.92 ; \mathrm{df}=14 ; p=0.37)$ or between the chronic-phase non-SE $(403.5 \pm 9.8 \mathrm{~g} ; n=27)$ and post-SE $(414.6 \pm 10.5 \mathrm{~g} ; n=58)$ subgroups (unpaired Student's $t$ test: $t=0.5$; $\mathrm{df}=83 ; p=0.8$ ).

\section{Spike output is increased in post-SE CA1 pyramidal cells}

Chronic-phase post-SE pyramidal cells fire more spikes than non-SE pyramidal cells in response to similar excitatory stimuli (Tamir et al., 2017). We have investigated this issue further in all four subgroups of neurons. Spikes and afterpotentials were evoked by 1-s-long positive current pulses applied, in steps of $0.15 \mathrm{nA}$, from 0.15 to $1.2 \mathrm{nA}$. The Ns increased with $I$. The firing responses evoked by $0.3 \mathrm{nA}$ current pulses in representative non-SE and post-SE chronic-phase neurons are shown in Figure $1 A$. Spike response gain values obtained from the $N$ s/I plots (see Materials and Methods) indicated that chronic-phase 
Table 2. Comparisons between non-SE and post-SE neurons with respect to spike response gain values (Ns// slopes) and sAHP/Ns slopes

\begin{tabular}{|c|c|c|c|c|c|c|c|c|}
\hline & \multicolumn{3}{|c|}{ Acute-phase neurons } & \multicolumn{3}{|c|}{ Chronic-phase neurons } & \multicolumn{2}{|l|}{$p$ Value } \\
\hline & $\begin{array}{l}\text { Non-SE } \\
(n=6)\end{array}$ & $\begin{array}{l}\text { Post-SE } \\
(n=6)\end{array}$ & $\begin{array}{l}p \text { Value } \\
\text { (non-SE vs } \\
\text { post-SE) }\end{array}$ & $\begin{array}{l}\text { Non-SE } \\
(n=12)\end{array}$ & $\begin{array}{l}\text { Post-SE } \\
(n=19)\end{array}$ & $\begin{array}{l}p \text { Value } \\
\text { (non-SE vs } \\
\text { post-SE) }\end{array}$ & $\begin{array}{l}\text { Acute vs } \\
\text { chronic } \\
\text { non-SE }\end{array}$ & $\begin{array}{l}\text { Acute vs } \\
\text { chronic } \\
\text { post-SE }\end{array}$ \\
\hline Ns// slope (Ns/nA) & $37.1 \pm 4.2$ & $53.6 \pm 5.9$ & $0.04^{*}$ & $30.2 \pm 3.9$ & $65.2 \pm 6.8$ & $0.0005^{* * *}$ & 0.30 & $0.01^{* *}$ \\
\hline Early-AHP/Ns slope (mV/Ns) & $0.32 \pm 0.11$ & $0.28 \pm 0.06$ & 0.20 & $0.32 \pm 0.07$ & $0.15 \pm 0.04$ & $0.009^{* *}$ & 0.62 & $0.01^{* *}$ \\
\hline Late-AHP/Ns slope (mV/Ns) & $0.05 \pm 0.06$ & $0.05 \pm 0.009$ & 0.78 & $0.07 \pm 0.02$ & $0.04 \pm 0.01$ & 0.35 & 0.45 & 0.41 \\
\hline
\end{tabular}

Significant differences were marked with asterisks as follows: ${ }^{*} p<0.05,{ }^{* *} p \leq 0.01$, and ${ }^{* * *} p \leq 0.001$.

post-SE neurons fire significantly many more spikes than respective non-SE neurons $(65.2 \pm 6.8$ and $30.2 \pm 3.9 \mathrm{~N} / \mathrm{I}$, respectively; $n=19$ and $n=8$, respectively; Mann-Whitney test, ${ }^{* *} p=$ 0.0005; Fig. 1B). Comparison between acute-phase subgroups indicated that the spike response gain of post-SE neurons was mildly, albeit significantly, larger than that of non-SE neurons (Table 2). However, it was significantly smaller than that of chronic-phase post-SE neurons (Table 2), indicating that the excitability of post-SE CA1 pyramidal cells continues to increase after the second post-SE day. In contrast, spike response gain values of acute- and chronic-phase non-SE neurons were similar, confirming that intrinsic neuronal excitability does not normally change over the time course of 5-6 weeks.

\section{sAHPs evoked by variable spike sequences are reduced in post-SE neurons}

We next investigated the relationship between spike output and sAHP amplitude in the four subgroups. Figure $1 C$ depicts representative traces of sAHPs evoked by the spike response to $0.3 \mathrm{nA}$ stimuli in chronic-phase non-SE neurons $(n=12$; Fig. $1 \mathrm{Ca})$ and post-SE neurons ( $n=19$; Fig. $1 C b)$. Increasing stimulus intensity augmented not only the number of evoked spikes, but also the amplitude of the resultant sAHPs. For quantification, we measured sAHP amplitudes at two time points following the end of the depolarizing pulse (Fig. $1 \mathrm{Ca}$, inset). The early sAHP amplitude was measured at $1 \mathrm{~s}$, at which time the sAHP no longer overlaps with the medium-duration AHP (the latter afterpotential lasts $\sim 200 \mathrm{~ms}$; Storm, 1989). The late sAHP amplitude was measured at $7 \mathrm{~s}$, at which time the contribution of $\mathrm{K}_{\mathrm{Ca}}$-sAHP to the composite sAHP is small (Gulledge et al., 2013; Tiwari et al., 2018).

Plots of early sAHP amplitudes (Fig. 1Da) and late sAHP amplitudes (Fig. $1 D b$ ) versus Ns were nearly linear in each animal subgroup. Therefore, these plots were fitted with linear regression lines, whose slopes (sAHP/Ns slopes) were used for statistical comparisons (see Materials and Methods). Chronic-phase non-SE neurons ( $n=12$; Fig. $1 \mathrm{Ca}$ ) displayed a significantly much larger early sAHP/Ns slope than post-SE neurons $(n=19$; Fig. $1 C b ; 0.32 \pm 0.07$ and $0.15 \pm 0.04 \mathrm{mV} / \mathrm{Ns}$, respectively; MannWhitney test, ${ }^{* *} p=0.009$; Fig. $\left.1 D a\right)$. No differences in the late sAHP/Ns slopes were found between the two groups of neurons $(0.07 \pm 0.02$ vs $0.04 \pm 0.01 \mathrm{mV} / \mathrm{Ns}$, respectively; Mann-Whitney test, $p=0.35$; Fig. $1 D b$ ). These results indicate that the higher spike response gain of chronic post-SE neurons is associated with, and likely caused by, smaller early sAHPs.

In acute-phase neurons, the early and late sAHP/Ns slopes in non-SE and in post-SE neurons were similar (Table 2). These results indicate that the sAHPs are not modified $2 \mathrm{~d}$ after pilocarpine-SE, but decrease thereafter. Congruently, chronicphase post-SE neurons displayed a significantly smaller early sAHP/Ns slope than acute-phase post-SE neurons, whereas early and late sAHP/Ns slopes in both chronic- and acute-phase non-SE neurons were the same (Table 2).
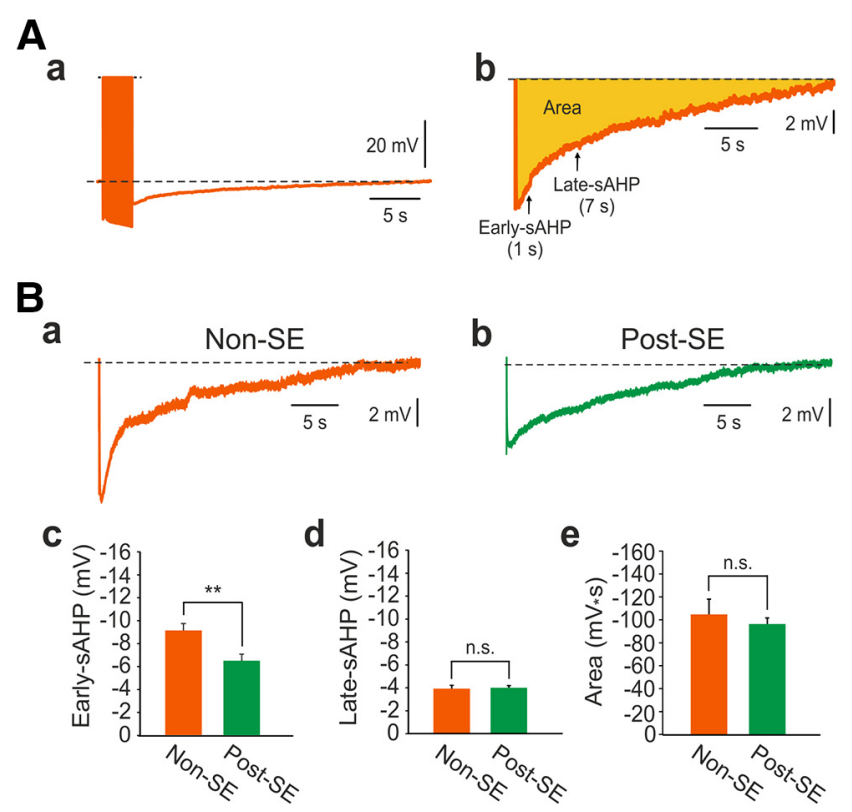

Figure 2. The SAHPs evoked by stereotyped spike trains in chronic-phase non-SE and post-SE neurons. Aa, A representative recording of an SAHP in a non-SE neuron following a train of 150 spikes elicited at $50 \mathrm{~Hz}$ (spikes are truncated) from resting $V_{m}$ of $-70 \mathrm{mV}$ (dashed line). $\boldsymbol{b}$, Enlarged depiction of the SAHP in $\boldsymbol{a}$, showing the three measures of sAHP size: Early sAHP (1 s after spike train), Late SAHP (7 $s$ after spike train), and Area (colored region between baseline and $S A H P) . B \boldsymbol{a}, \boldsymbol{b}$, Representative recordings of SAHPs evoked by spike trains in a non-SE neuron ( $\boldsymbol{a}$ ) and in a post-SE neuron $(\boldsymbol{b}) . \boldsymbol{B} \boldsymbol{c}-\boldsymbol{e}$, The bar diagrams show the measured values of the SAHPs in the two subgroups of neurons: $\boldsymbol{c}$, early sAHP amplitudes; $\boldsymbol{d}$, late sAHP amplitude; $\boldsymbol{e}$, SAHP area. The early sAHP was significantly smaller in the post-SE neurons. ${ }^{* *} p \leq 0.01$. n.S., Not significant.

Together, our results show that the reduction in early sAHP amplitude and the associated increase in spike output in chronicphase post-SE neurons are a manifestation of the chronic epileptic condition. Therefore, we restricted the following experiments to changes in sAHPs in chronic-phase neurons.

\section{sAHPs evoked by stereotyped spike trains are reduced in post-SE neurons}

We further investigated the mechanisms of sAHP reduction in chronic-phase post-SE neurons using sAHPs evoked by stereotyped spike trains. To that end, we evoked sAHPs with 150 brief (2-ms-long) suprathreshold depolarizing current pulses delivered at $50 \mathrm{~Hz}$. The size of each sAHP was assessed using early and late sAHP amplitudes, as well as the integrated "area under the curve" (simply, "area"; see Materials and Methods; Fig. 2Ab).

Representative sAHPs recorded in non-SE $(n=30)$ and post-SE neurons $(n=40)$ are shown in Figure $2 B$. The early sAHP amplitudes in post-SE neurons were significantly reduced compared with non-SE neurons (to $71.2 \%$ of control; $-9.1 \pm 0.6$ and $-6.5 \pm 0.6 \mathrm{mV}$, respectively; unpaired Student's $t$ test: $t=$ $3.2 ; \mathrm{df}=68 ;{ }^{* *} p=0.002$; Fig. $2 B c$ ). However, no differences in 
late sAHP amplitudes $(-3.9 \pm 0.3$ and $-4.4 \pm 0.3 \mathrm{mV}$, respectively; unpaired Student's $t$ test: $t=0.9$; df $=68 ; p=0.82$; Fig. $2 B d)$ and in areas $(-97.3 \pm 6.9$ and $-96.4 \pm 6.9 \mathrm{mV}^{\star} \mathrm{s}$, respectively; unpaired Student's $t$ test: $t=1.8 ; \mathrm{df}=68 ; p=0.07$; Fig. $2 \mathrm{Be}$ ) were found between the two groups.

\section{Differential conductance changes during the sAHPs in non-SE and post-SE neurons}

The preferential decrease in early sAHP in post-SE neurons suggests that the $\mathrm{K}_{\mathrm{Ca}^{-}}$ sAHP component, but not the NKAcomponent, is reduced in these neurons (Tiwari et al., 2018). We tested this notion using four different approaches. First, we monitored the membrane conductance during the sAHP in non-SE and post-SE neurons. To that end, negative current pulses ( $50 \mathrm{~ms},-50 \mathrm{pA}$ ) were applied continuously at $2 \mathrm{~Hz}$ while also evoking sAHPs with trains of 150 spikes. The amplitudes of the resultant brief hyperpolarizations were measured $\sim 4 \mathrm{~s}$ before the spike train (baseline conductance measurement), as well as early (within $250 \mathrm{~ms}$ to $1 \mathrm{~s})$ and late $(\sim 7 \mathrm{~s})$ after the spike train (i.e., during the sAHP; Fig. $3 A a)$. In the non-SE group $(n=8)$, the early amplitudes were significantly reduced compared with baseline values (to $68.6 \pm 6.5 \% ; t=3.0 ; \mathrm{df}=14 ;{ }^{* *} p=$ $0.009)$, whereas the late amplitudes were unchanged (102.5 \pm $9.1 \% ; t=0.21 ; \mathrm{df}=14 ; p=0.839$; Fig. $3 A a, b, c)$. In contrast, the amplitudes of the brief test hyperpolarizations were not significantly reduced during the SAHP in post-SE neurons $(n=9)$ at both time points (early: $84.8 \pm 6.5 \%$; unpaired Student's $t$ test, $t=1.7$; df $=16 ; p=0.157$; late: $94.1 \pm 7.4 \%$; unpaired Student's $t$ test, $t=0.6$; df $=16$; $p=0.616$; Fig. $3 B a, b, c)$. Because the $\mathrm{K}_{\mathrm{Ca}}$-sAHP component, but not the NKA-sAHP component (provided HCN channels are blocked; Tiwari et al., 2018), is associated with a conductance increase, these findings support the notion that $\mathrm{K}_{\mathrm{Ca}}-\mathrm{sAHP}$ is preferentially reduced in chronic-phase post-SE neurons. They also indicate that the early sAHP reduction in post-SE neurons is not due to shunting by activation of a depolarizing membrane conductance.

\section{Blocking NKA activity differentially affects the sAHPs in non-SE and post-SE neurons}

We next monitored the effects of blocking NKA transport activity. In non-SE neurons $(n=10)$, bath-applied ouabain $(10 \mu \mathrm{M})$ significantly, albeit partially, reduced early sAHP amplitudes (to $74.4 \%$ of control; from $-8.6 \pm 0.8$ to $-6.4 \pm 0.7 \mathrm{mV}$; paired Student's $t$ test: $t=2.9$; df $=9 ;{ }^{*} p=0.02$; Fig. $\left.4 A a, b\right)$. Late sAHP amplitudes (to $23.1 \%$ of control; from $-4.1 \pm 0.5$ to $-0.9 \pm 0.3$ $\mathrm{mV}$; paired Student's $t$ test: $t=6.6$; $\mathrm{df}=9 ;{ }^{* * *} p=0.0001$; Fig. $4 A a, c$ ) and sAHP areas (to $29.8 \%$ of control; from $-95.9 \pm 12.1$ to $-28.6 \pm 6.1 \mathrm{mV}^{\star} \mathrm{s}$; paired Student's $t$ test: $t=6.5$; $\mathrm{df}=9$; ${ }^{* *} p=0.0001$; Fig. $\left.4 A a, d\right)$ were more strongly reduced by ouabain. These findings confirm that in non-SE neurons, NKA activity contributes partially to the early part of the sAHP and even more to its late part (Tiwari et al., 2018).
B

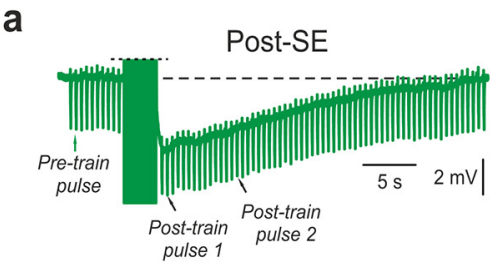

b

C

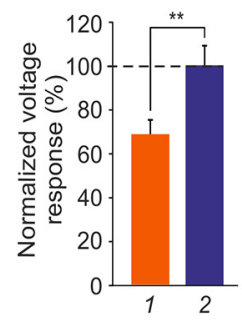

C

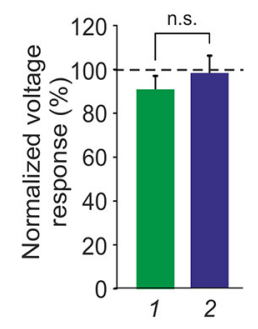

Figure 3. Membrane conductance changes during SAHPs in chronic-phase non-SE and post-SE neurons. $\boldsymbol{A}$, To monitor the me conductance during an SAHP, a train of negative current pulses ( $50 \mathrm{~ms},-50 \mathrm{pA}$ ) was applied at $2 \mathrm{~Hz}$ before and after membrane conductance at this time point. $\boldsymbol{B}$, Same as in $\boldsymbol{A}$, but for post-SE neurons. The small reduction in post-train pulse 1 amplitude is not significant. ${ }^{* *} p \leq 0.01$. n.S., Not significant.

In post-SE neurons $(n=6)$, however, ouabain reduced almost completely the early sAHP amplitudes (to $17.6 \%$ of control; from $-6.8 \pm 0.7$ to $-1.2 \pm 0.5 \mathrm{mV}$; paired Student's $t$ test: $t=5.1 ; \mathrm{df}=$ 5 ; $p={ }^{*} 0.004$; Fig. $\left.4 B a, b\right)$ and the late sAHP amplitudes (to $14.0 \%$ of control; from $-4.6 \pm 0.7$ to $-0.6 \pm 0.4 \mathrm{mV}$; paired Student's $t$ test: $t=4.1 ; \mathrm{df}=5 ;{ }^{* *} p=0.0005$; Fig. $\left.4 B a, c\right)$, as well as sAHP areas (to $3.3 \%$ of control; from $-105.2 \pm 14.1$ to $-3.5 \pm$ $1.1 \mathrm{mV}^{\star}$ s; paired Student's $t$ test: $t=6.9$; df $=5 ;{ }^{* *} p=0.0001$; Fig. $4 B a, d)$. These results further support the notion that sAHPs in the post-SE neurons lack a significant $\mathrm{K}_{\mathrm{Ca}}$-sAHP component.

Blocking voltage-gated $\mathrm{Ca}^{2+}$ currents differentially affects the sAHPs in non-SE and post-SE neurons on the SAHP

We further tested the latter hypothesis using $\mathrm{Cd}+\mathrm{Ni}$ aCSF to block voltage-gated $\mathrm{Ca}^{2+}$ channels, thereby eliminating the $\mathrm{K}_{\mathrm{Ca}^{-}}$sAHP component (Tiwari et al., 2018). In non-SE neurons $(n=$ 10 ), this treatment reduced preferentially the early sAHP amplitudes (to $56.0 \%$ of control; from $-9.1 \pm 0.6$ to $-5.1 \pm 0.8 \mathrm{mV}$; paired Student's $t$ test: $t=4.7$; $\mathrm{df}=9 ;{ }^{* *} p=0.001$; Fig. $\left.5 A a, b\right)$, but also the late sAHP amplitudes (to $69.3 \%$ of control; from $-3.9 \pm 0.3$ to $-2.7 \pm 0.5 \mathrm{mV}$; paired Student's $t$ test: $t=2.1 ; \mathrm{df}=$ 9 ; ${ }^{\star} p=0.04$; Fig. $5 A a, c$ ) and the sAHP areas (to $63.5 \%$ of control; $-104.6 \pm 7.3$ to $-66.8 \pm 8.2 \mathrm{mV}^{\star} \mathrm{s}$; paired Student's $t$ test: $t=$ $4.9 ; \mathrm{df}=9 ;{ }^{* *} p=0.002$; Fig. $\left.5 A a, d\right)$. In contrast, the same treatment in post-SE neurons $(n=18)$ affected neither early sAHP amplitudes (from $-6.5 \pm 0.6$ to $-5.9 \pm 0.8 \mathrm{mV}$; paired Student's $t$ test: $t=1.5$; df $=17 ; p=0.6$; Fig. $5 B a, b)$ nor late sAHP amplitudes (from $-4.4 \pm 0.3$ to $-4.1 \pm 0.5 \mathrm{mV}$; paired Student's $t$ test: $t=1.7$; df $=17 ; p=0.25$; Fig. $5 B a, c$ ), nor sAHP areas (from $-92.0 \pm 4.2$ to $-76.1 \pm 5.0 \mathrm{mV}^{\star} \mathrm{s}$; paired Student's $t$ test: $t=2.0$; $\mathrm{df}=17 ; p=0.056$; Fig. $5 B a, d)$. This differential effect of $\mathrm{Cd}+\mathrm{Ni}$ aCSF also indicates the absence of a $\mathrm{K}_{\mathrm{Ca}}$-sAHP component in post-SE neurons. 
$\mathrm{A}_{\mathrm{a}}$

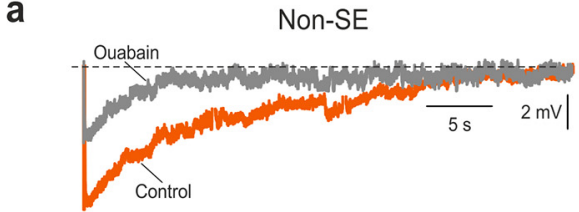

b

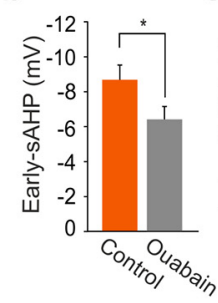

C

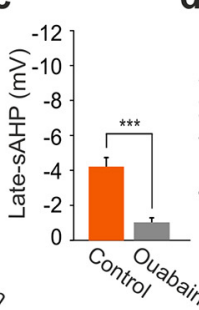

d

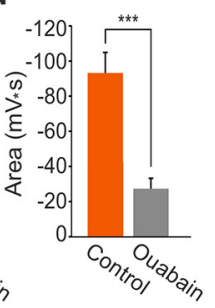

B

a

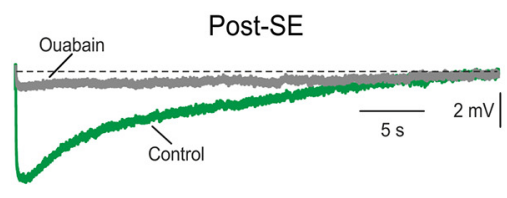

b

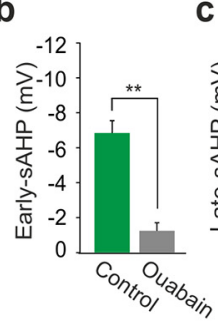

C

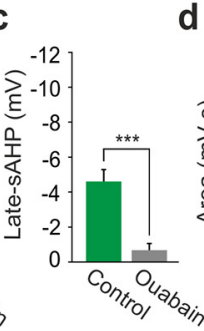

d

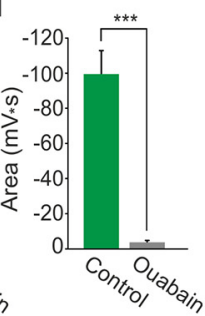

Figure 4. Differential ouabain sensitivity in chronic-phase non-SE and post-SE neurons. $\boldsymbol{A}$, The effect of ouabain on the SAHPs in non-SE neurons. $\boldsymbol{a}$, Two overlaid representative traces of the SAHPs in a single neuron before, and $20 \mathrm{~min}$ after, the application of $10 \mu \mathrm{m}$ ouabain to the slice. $\boldsymbol{b}$ - $\boldsymbol{d}$, Summary bar diagrams showing the measured values of the sAHPs before (Control) and after drug application (Ouabain): $\boldsymbol{b}$, Early sAHP amplitudes; $\boldsymbol{c}$, Late sAHP amplitudes; and $\boldsymbol{d}$, Areas. While both early and late sAHPs are reduced by ouabain, the reduction of the late sAHP is more intense, similar to the reduction in area. $\boldsymbol{B}$, Same as in $\boldsymbol{A}$, but for chronic-phase post-SE neurons. Note the equal and strong suppression of both early and late $5 A H P s .{ }^{*} p<0.05,{ }^{* *} p \leq 0.01,{ }^{* * *} p \leq 0.001$.

\section{Blocking KCa3.1 current differentially affects the sAHPs in non-SE and post-SE neurons}

For the last test of the latter hypothesis, we used the selective KCa3.1 channel antagonist TRAM34, which was previously shown to suppress $\mathrm{K}_{\mathrm{Ca}}$-sAHP CA1 pyramidal cells (King et al., 2015; Turner et al., 2016; Tiwari et al., 2018). In non-SE neurons $(n=6)$, bath-applied TRAM34 $(5 \mu \mathrm{M})$ reduced most strongly the early sAHP amplitudes (to $56.1 \%$ of control; from $-10.7 \pm 0.9$ to $-6.0 \pm 0.8 \mathrm{mV}$; paired Student's $t$ test: $t=10.4$; df $=5 ;{ }^{*} p=$ 0.004; Fig. 5Ca,b), but also the late sAHP amplitudes (to $65.8 \%$ of control; from $-4.42 \pm 0.94$ to $-2.91 \pm 0.42 \mathrm{mV}$; paired Student's $t$ test: $t=2.2$; df $=5 ;{ }^{\star} p=0.04$; Fig. $\left.5 C a, c\right)$ and the sAHP areas (to $64.4 \%$ of control; from $-87.3 \pm 13.6$ to $-56.2 \pm 10.1$ $\mathrm{mV}^{\star} \mathrm{s}$; paired Student's $t$ test: $t=4.6 ; \mathrm{df}=5 ;{ }^{*} p=0.006$; Fig. $5 \mathrm{Ca}, d)$. In contrast, in post-SE neurons $(n=7)$ TRAM34 had no significant effect on early sAHP amplitudes (from $-6.3 \pm 0.8$ to $-5.9 \pm 0.7 \mathrm{mV}$; paired Student's $t$ test: $t=0.3 ; \mathrm{df}=6 ; p=0.8$; Fig. $5 D a, b$ ), late sAHP amplitudes (from $-4.38 \pm 0.44$ to $-3.94 \pm 0.29 \mathrm{mV}$; paired Student's $t$ test; $t=1.2 ; \mathrm{df}=6 ; p=0.42$; Fig. $5 \mathrm{Da}, \mathrm{c}$ ), and sAHP areas (from $-88.3 \pm 8.5$ to $-88.5 \pm 9.9$ $\mathrm{mV}^{\star} \mathrm{s}$; paired Student's $t$ test: $t=0.05$; $\mathrm{df}=6$; $p=0.98$; Fig. $5 D a, d)$. This differential effect of TRAM34 also indicates the absence of a $\mathrm{K}_{\mathrm{Ca}}$-SAHP component in post-SE neurons.

As further analyses, we compared chronic-phase non-SE and post-SE neurons with respect to sAHPs recorded under $\mathrm{Cd}+\mathrm{Ni}$ or TRAM34. In these conditions, the sAHPs consist almost entirely of the NKA-sAHP component (Tiwari et al., 2018). In slices perfused with $\mathrm{Cd}+\mathrm{Ni}$ aCSF, the early sAHP amplitudes $(-5.1 \pm$ 0.8 and $-5.9 \pm 0.8 \mathrm{mV}$; unpaired Student's $t$ test: $t=0.6 ; \mathrm{df}=26$; $p=0.50$; Fig. 5Ea), late sAHP amplitudes $(-2.72 \pm 0.49$ and $-4.13 \pm 0.49 \mathrm{mV}$; unpaired Student's $t$ test: $t=1.8$; $\mathrm{df}=26 ; p=$ 0.08; Fig. $5 E b)$, and sAHP areas $(-66.8 \pm 8.2$ and $-76.1 \pm 5.0$ $\mathrm{mV}^{\star} \mathrm{s}$; unpaired Student's $t$ test: $t=1.0$; df $=26 ; p=0.08$; Fig. $5 E c)$ of non-SE neurons $(n=10)$ and post-SE neurons $(n=18)$ were similar. Likewise, in slices treated with TRAM34, early sAHP amplitudes $(-6.0 \pm 0.8$ and $-5.9 \pm 0.7 \mathrm{mV}$; unpaired Student's $t$ test: $t=0.09 ; \mathrm{df}=11 ; p=0.9$; Fig. $5 \mathrm{Fa}$ ) and late sAHP amplitudes $(-2.9 \pm 0.4$ to $-3.9 \pm 0.3 \mathrm{mV}$; unpaired Student's $t$ test: $t=2.0 ; \mathrm{df}=11 ; p=0.06$; Fig. $5 F b)$ were similar in the two groups ( $n=6$ and 7, respectively). Intriguingly, NKA-sAHP areas were significantly larger in post-SE neurons (by $57.6 \%$ of control; $-56.2 \pm 10.1$ to $-88.5 \pm 9.9 \mathrm{mV}^{\star}$ s; unpaired Student's $t$ test: $t=2.3$; df $=11 ;{ }^{*} p=0.04$; Fig. $5 F c$ ). As the latter effect was not seen in $\mathrm{Cd}+\mathrm{Ni}$ aCSF, we conclude that the NKA-sAHP component is not altered appreciably in post-SE neurons.

\section{Isolated $\mathrm{K}_{\mathrm{Ca}}-\mathrm{sAHP}$ and $I_{\text {sAHP }}$ are reduced in post-SE neurons}

Isolation of $\mathrm{K}_{\mathrm{Ca}}$-sAHP by blocking NKA activity provides only a limited time window for monitoring this component (Fig. 4), as protracted NKA inhibition leads to the dissipation of ion gradients and to the deterioration of cellular function. Therefore, to record "pure" $\mathrm{K}_{\mathrm{Ca}}$-sAHP, we perfused slices with an aCSF whose composition was designed to block $\mathrm{Na}^{+}$-dependent spikes and to allow the evocation of $\mathrm{Ca}^{2+}$ spikes (Lancaster and Nicoll, 1987; Yue and Yaari, 2006; Tiwari et al., 2018; see Materials and Methods). These spikes were readily evoked by 90 -ms-long depolarizing current pulses of $0.4-0.6 \mathrm{nA}$. In the same neurons and experimental conditions, we also used discontinuous voltageclamp recordings to monitor the current generating the $\mathrm{K}_{\mathrm{Ca}}$-sAHP, referred to as $I_{\mathrm{sAHP}}$. The latter current was evoked by 100 -ms-long voltage steps to $-15 \mathrm{mV}$ from a holding potential of $-70 \mathrm{mV}$ (see Materials and Methods).

A representative $\mathrm{Ca}^{2+}$ spike followed by a $\mathrm{K}_{\mathrm{Ca}}-\mathrm{sAHP}$ recorded in a chronic-phase non-SE neuron is shown in Figure 6Aa. Its underlying $I_{\text {sAHP }}$ is shown in Figure $6 A b$. In non-SE neurons, the time to peak, peak amplitude, and duration of isolated $\mathrm{K}_{\mathrm{Ca}}$ sAHPs averaged $250.2 \pm 1.0 \mathrm{~ms},-9.5 \pm 1.2 \mathrm{mV}$, and $4.3 \pm 0.3 \mathrm{~s}$, respectively $(n=23)$.

In chronic-phase post-SE neurons $(n=23), \mathrm{K}_{\mathrm{Ca}}$-sAHPs (Fig. $6 \mathrm{Ba}$ ) were remarkably $(44.7 \%)$ smaller in amplitude compared with non-SE neurons $(-4.2 \pm 0.6$ and $-9.5 \pm 1.2 \mathrm{mV}$, respectively; unpaired Student's $t$ test: $t=4.0 ; \mathrm{df}=44 ;{ }^{* * *} p=0.0002$; Fig. $6 G$ ). These differences were not consequent to changes in the $\mathrm{Ca}^{2+}$ spikes, as no differences were found in their thresholds $(0.48 \pm 0.04$ and $0.58 \pm 0.05 \mathrm{nA}$, respectively; unpaired Student's $t$ test: $t=1.6 ; \mathrm{df}=44 ; p=0.12)$ and peak amplitudes $(63.1 \pm 2.2$ and $63.4 \pm 2.8 \mathrm{mV}$, respectively; unpaired Student's $t$ test: $t=$ $0.08 ; \mathrm{df}=44 ; p=0.92)$. Congruently, the $I_{\mathrm{sAHP}}$ values recorded in post-SE neurons (Fig. $6 \mathrm{Bb}$ ) were also much smaller $(33.7 \%)$ than in non-SE neurons $(56.1 \pm 9.3$ and $166.0 \pm 11.3 \mathrm{pA}$, respectively; unpaired Student's $t$ test: $t=7.5 ; \mathrm{df}=44 ;{ }^{* * *} p=0.0001$; Fig. $6 H)$. 
A

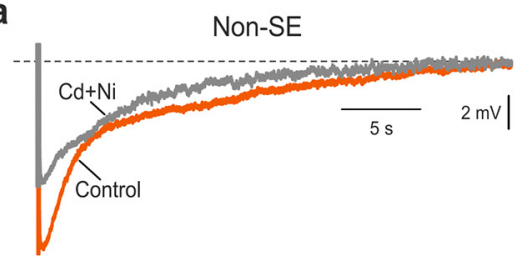

b
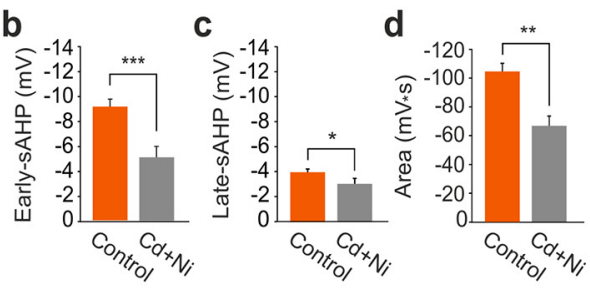

$\mathrm{C}_{\mathrm{a}}$

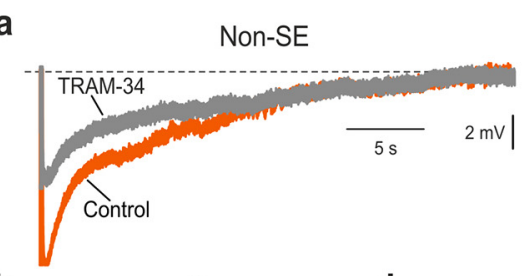

C

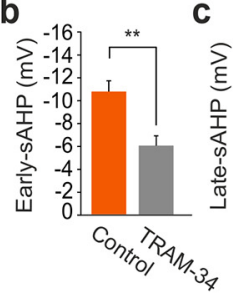

E

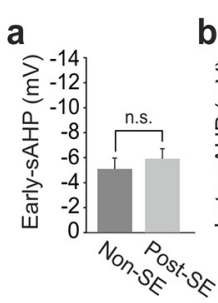

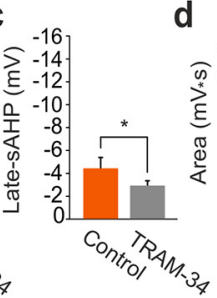

d

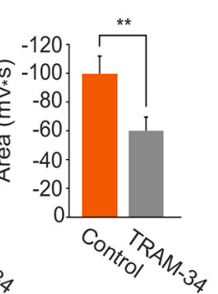

B

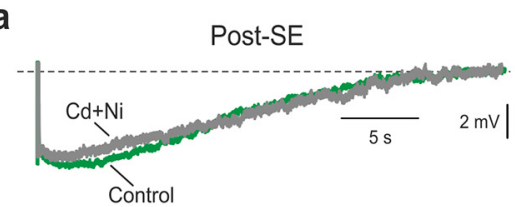

b
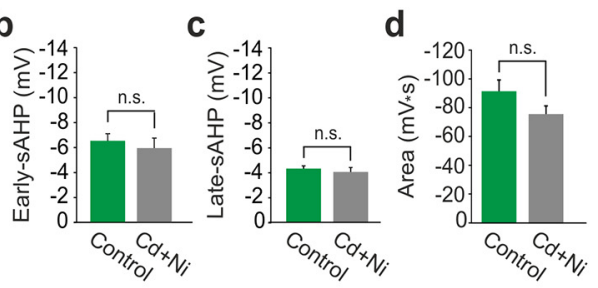

$D_{a}$

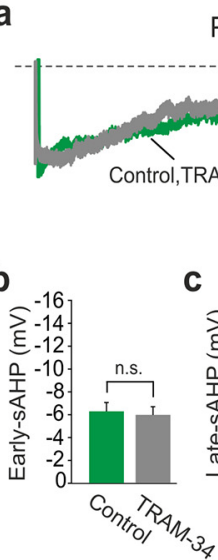

Post-SE

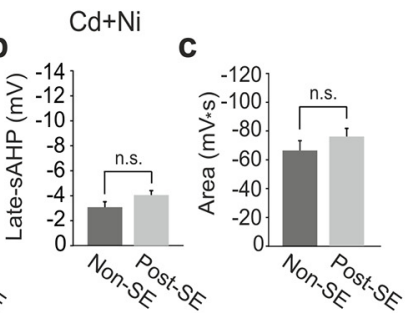

F

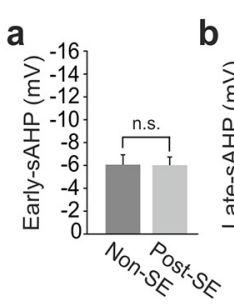

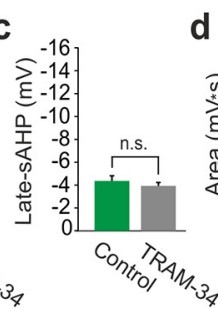

d

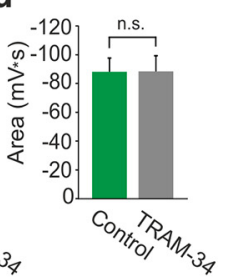

TRAM-34

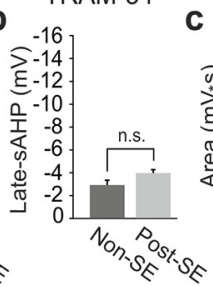

C

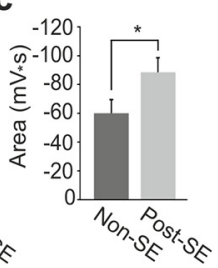

Figure 5. Blocking voltage-gated $\mathrm{Ca}^{2+}$ channels or KCa3.1 channels differentially affects sAHPs in chronic-phase non-SE and post-SE neurons. $A$, The effect of changing from standard aCSF to $\mathrm{Cd}+\mathrm{Ni}$ aCSF on the sAHPs in non-SE neurons. $\boldsymbol{a}$, Two overlaid representative traces of the sAHPs in a single neuron before, and 30 min after, changing from standard aCSF (Control) to Cd + Ni aCSF. $\boldsymbol{b}$ - $\boldsymbol{d}$, Summary bar diagrams showing early SAHP amplitudes (b), late SAHP amplitudes $(\boldsymbol{c})$, and SAHP areas (d) before (Control) and after changing to $\mathrm{Cd}+\mathrm{Ni}$. While both early and late sAHP amplitudes are reduced by $\mathrm{Cd}+\mathrm{Ni}$, the reduction in early sAHP amplitude is more conspicuous. $B$, Same as in $A$, but for post-SE neurons. Note that changing to $\mathrm{Cd}+\mathrm{NiaCSF}$ has no effect on the sAHPs in these neurons. $\boldsymbol{C}$, The effect of TRAM34 on the sAHPs in chronic-phase non-SE neurons. $\boldsymbol{a}$, Two overlaid representative traces of the sAHPs in a single neuron before, and 30 min after, applying 5

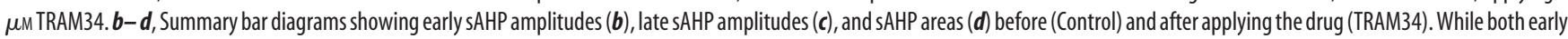
and late sAHP amplitudes are reduced by TRAM34, the reduction in early sAHP amplitude is more conspicuous. D, Same as in $C$, but for post-SE neurons. Note that TRAM34 has no effect on the sAHPs in these neurons. $\boldsymbol{E}$, Comparison of the SAHPs recorded in Cd+Ni aCSF (i.e., the isolated NKA-sAHPS) between non-SE and post-SE neurons. $\boldsymbol{a}-\boldsymbol{c}$, The summary bar diagrams show early sAHP amplitudes $(\boldsymbol{a})$, late sAHP amplitudes $(\boldsymbol{b})$, and sAHP areas ( $\boldsymbol{c}$ ) in the two subgroups. No significant differences are found. $\boldsymbol{F}$, Comparison of the sAHPs recorded in TRAM34 (predominantly NKA-sAHPs) between non-SE and post-SE neurons. $\boldsymbol{a}-\boldsymbol{c}$, The summary bar diagrams show early sAHP amplitudes $(\boldsymbol{a})$, late sAHP amplitudes $(\boldsymbol{b})$, and $\mathrm{sAHP}$ areas (c) in the two subgroups. No differences in early and late SAHPs are found between the two subgroups of neurons, but the sAHP area is significantly enhanced in the latter subgroup. ${ }^{*} p<0.05,{ }^{* *} p \leq 0.01$. n.s., Not significant.

Together, these data indicate that $\mathrm{K}_{\mathrm{Ca}}$-sAHP is markedly reduced in chronic-phase post-SE neurons due to a decrease in its underlying $I_{\mathrm{sAHP}}$.

\section{Protein kinase A blockers normalize $\mathrm{K}_{\mathrm{Ca}}$-sAHP, $I_{\mathrm{sAHP}}$, and} spike output in post-SE neurons

Activation of PKA by cAMP inhibits $\mathrm{K}_{\mathrm{Ca}}$-sAHP and $I_{\mathrm{sAHP}}$ in CA1 pyramidal cells (Madison and Nicoll, 1986; Pedarzani and Storm, 1993, 1995). Therefore, we tested whether $\mathrm{K}_{\mathrm{Ca}}$-sAHP reduction in chronic-phase post-SE neurons might be mediated by persis- tently activated PKA. To that end, we treated chronic-phase slices with the cell-permeable PKA inhibitor RPcAMP (Dostmann et al., 1990; Wang et al., 1991). The drug (100 $\mu \mathrm{M})$ was applied to the slice $1 \mathrm{~h}$ before and throughout the recording session. In non-SE neurons, $\mathrm{K}_{\mathrm{Ca}}$-sAHP amplitudes in RPcAMP-treated neurons $(-9.0 \pm 1.3 \mathrm{mV} ; n=6)$ were similar to those in untreated neurons $(-9.5 \pm 1.2 \mathrm{mV} ; n=23$; unpaired Student's $t$ test: $t=0.2$; $\mathrm{df}=27 ; p=0.76$; Fig. $6 G)$. Likewise, $I_{\mathrm{sAHP}}$ amplitudes were also similar in the RPcAMP-treated subgroup $(142.7 \pm 12.6 \mathrm{pA})$ and the untreated subgroup $(166.0 \pm 11.3 \mathrm{pA}$; unpaired Student's $t$ 
A

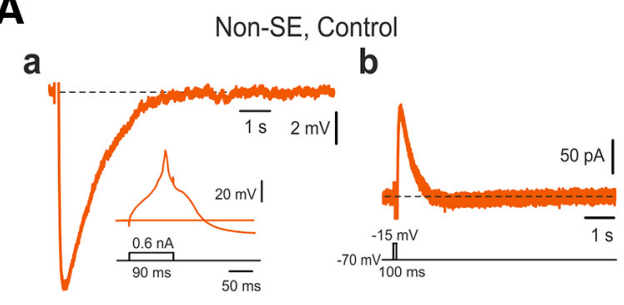

C

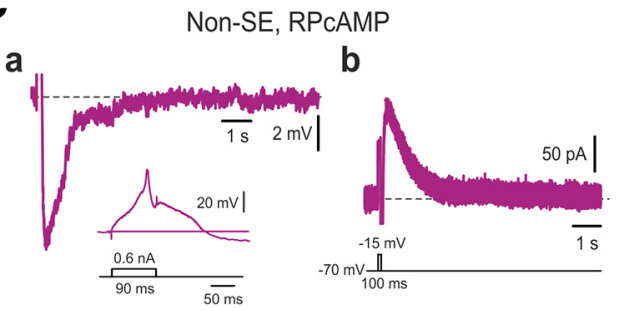

E

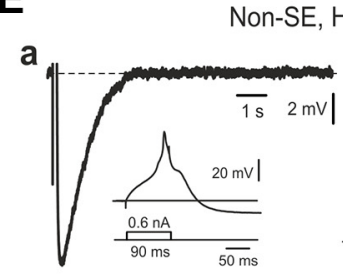

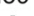

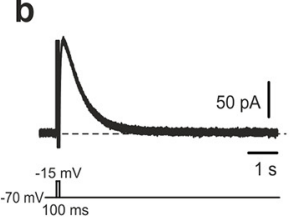

B

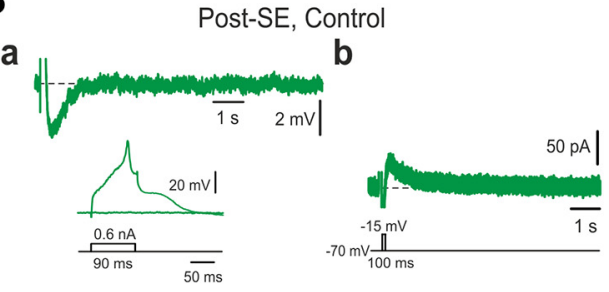

D

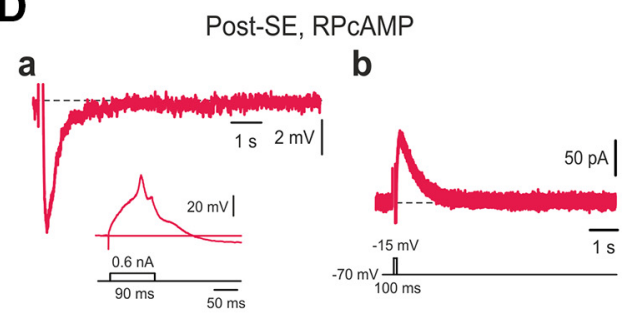

$\mathbf{F}$

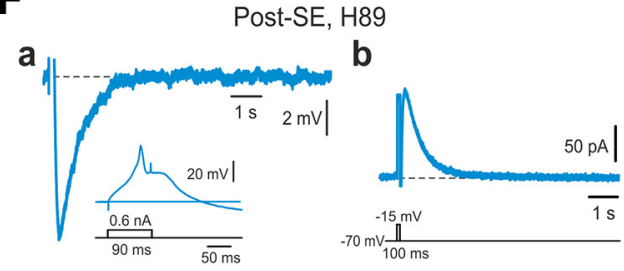

G

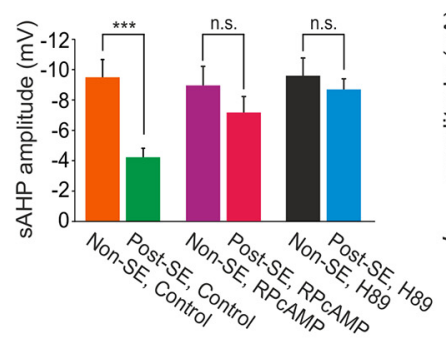

I

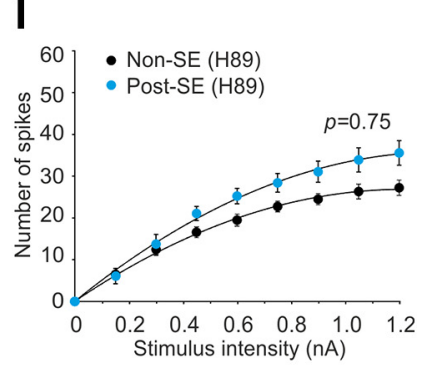

Figure 6. PKA inhibition with RPCAMP or H89 largely restores the suppressed $\mathrm{K}_{\mathrm{Ca}}-\mathrm{SAHP}$ and $I_{\text {sAHP }}$ in chronic-phase post-SE neurons. Aa, $\boldsymbol{b}$, Representative recordings of a $\mathrm{K}_{\mathrm{Ca}}$-SAHP evoked by a $\mathrm{Ca}^{2+}$ spike (shown in inset; $\boldsymbol{a}$ ) and an $I_{\text {SAHP }}$ evoked by a depolarizing pulse $(\boldsymbol{b})$ in a non-SE neuron. $\boldsymbol{B}$, Same as in $\boldsymbol{A}$, but recordings were made in a post-SE neuron. $\boldsymbol{C}$, Same as in $\boldsymbol{A}$, but recordings were made in non-SE slices treated for $>1 \mathrm{~h}$ with the PKA inhibitor RPCAMP $(100 \mu \mathrm{M})$. $\boldsymbol{D}$, Same as in $\boldsymbol{B}$, but recordings were made in post-SE slices treated for $>1 \mathrm{~h}$ with the PKA inhibitor RPcAMP. $\boldsymbol{E}$, Same as in $\boldsymbol{C}$, but recordings were made in non-SE slices treated for $>1 \mathrm{~h}$ with the PKA inhibitor H89 $(10 \mu \mathrm{M})$. $\boldsymbol{F}$, Same as in $\boldsymbol{D}$, but recordings were made in post-SE slices treated for $>1 \mathrm{~h}$ with the PKA inhibitor H89. Note that in this condition the $\mathrm{K}_{\mathrm{Ca}}-\mathrm{SAHP}$ and $\mathrm{I}_{\mathrm{SAHP}}$ in the non-SE and post-SE neurons appear similar in size. G, Summary bar diagram of $\mathrm{K}_{\mathrm{Ca}}$-SAHP amplitudes (measured at the peak of the SAHP) in non-SE and post-SE neurons recorded in normal aCSF and in RPCAMP or H89-containing aCSF. $\boldsymbol{H}$, Summary bar diagram of $I_{\text {sAHP }}$ amplitudes (measured at peak current) in non-SE and post-SE neurons recorded in normal aCSF and RPCAMP or H89 containing aCSF. Note that both $\mathrm{K}_{\mathrm{Ca}}$-SAHP and $I_{\text {SAHP }}$ values are markedly and significantly reduced in post-SE neurons, and are largely restored by treating slices with PKA inhibitors (RPCAMP or H89). I, Spikes were evoked by a series of 1-s-long depolarizing current pulses in non-SE and post-SE neurons, all treated with H89. The two plots depict the number of spikes versus stimulus intensity in the two groups of neurons. Although post-SE neurons fire more spikes, the difference between the two plots is not significant, indicating that $\mathrm{H} 89$ treatment reduces the excitability of post-SE neurons to near the non-SE level. ${ }^{* *} p \leq 0.001$. n.s., Not significant.

test: $t=1.0 ; \mathrm{df}=27 ; p=0.20$; Fig. $6 H$ ). Thus, inhibiting PKA with RPcAMP by itself had no significant effect on $\mathrm{K}_{\mathrm{Ca}^{-}}$sAHP in non-SE neurons.

Intriguingly, $\mathrm{K}_{\mathrm{Ca}}$-sAHP amplitudes in RPcAMP-treated post-SE neurons $(-7.1 \pm 1.1 \mathrm{mV} ; n=5$; Fig. $6 \mathrm{Da})$ were significantly 1.7-fold larger than in untreated post-SE neurons $(-4.2 \pm$ $0.6 \mathrm{mV} ; n=23$; unpaired Student's $t$ test: $t=2.1$; df $=26 ;{ }^{\star} p=$ 0.02 ; Fig. $6 \mathrm{Ba}$ ) and slightly but insignificantly smaller $(79.7 \%)$ than those in drug-treated non-SE neurons treatment $(-9.0 \pm$ $1.3 \mathrm{mV} ; n=6$; unpaired Student's $t$ test: $t=0.7 ; \mathrm{df}=26 ; p=0.30$ Fig. $6 \mathrm{Ca}, \mathrm{G})$. Likewise, $I_{\mathrm{sAHP}}$ amplitudes in drug-treated post-SE neurons $(100.5 \pm 17.1 \mathrm{pA} ; n=5$; Fig. $6 \mathrm{Db})$ were significantly 1.8-fold larger than in untreated post-SE neurons $(56.1 \pm 9.3 \mathrm{pA}$; $n=23$; unpaired Student's $t$ test, $t=2.1 ; \mathrm{df}=26 ;{ }^{*} p=0.04$; Fig. $6 \mathrm{Bb})$ and slightly but insignificantly smaller in amplitude (70.4\%) than those in RPcAMP-treated non-SE neurons treat- ment $(142.7 \pm 12.6 \mathrm{pA} ; n=6$; unpaired Student's $t$ test: $t=1.5$; $\mathrm{df}=26 ; p=0.10$; Fig. $6 \mathrm{Cb}, \mathrm{H})$.

Treating non-SE neurons with RPcAMP did not affect $\mathrm{Ca}^{2+}$ spike rheobase currents (from $0.48 \pm 0.04$ to $0.54 \pm 0.09 \mathrm{nA}$; unpaired Student's $t$ test, $t=0.7 ; \mathrm{df}=27 ; p=0.57$ ) and amplitudes (from $63.1 \pm 2.2$ to $60.6 \pm 1.9 \mathrm{mV}$; unpaired Student's $t$ test: $t=0.6$; $\mathrm{df}=27 ; p=0.42$ ). Similarly in post-SE neurons, drug treatment did not affect $\mathrm{Ca}^{2+}$-spike rheobase currents (from $0.58 \pm 0.05$ to $0.62 \pm$ $0.10 \mathrm{nA}$; unpaired Student's $t$ test: $t=0.3$; df $=26 ; p=0.56)$ and amplitudes (from and $63.4 \pm 2.8$ to $58.2 \pm 1.8 \mathrm{mV}$; unpaired Student's $t$ test: $t=0.8$; df $=26 ; p=0.38$ ). Together, these results indicate that inhibiting PKA restores $\mathrm{K}_{\mathrm{Ca}}$-sAHP and its underlying current to nearly normal values.

We performed similar experiments using another cell-permeable PKA inhibitor, H89 (Chijiwa et al., 1990). The drug (10 $\mu \mathrm{M})$ was applied to the slice $1 \mathrm{~h}$ before and throughout the recording session. 
A

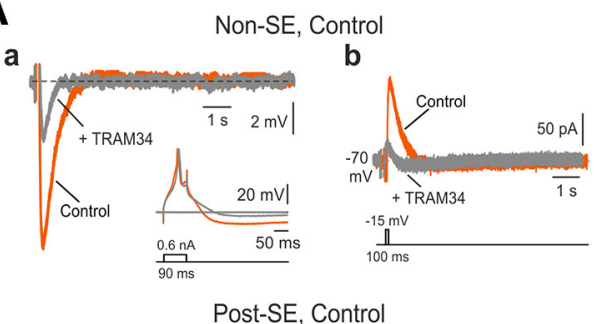

C

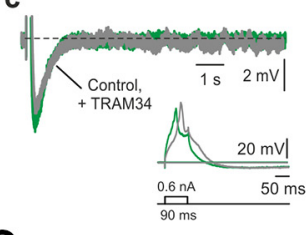

C

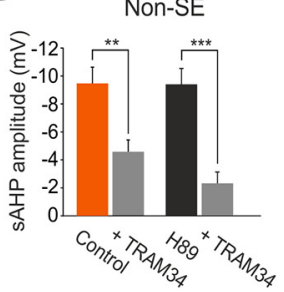

d

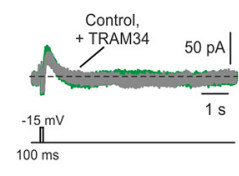

D

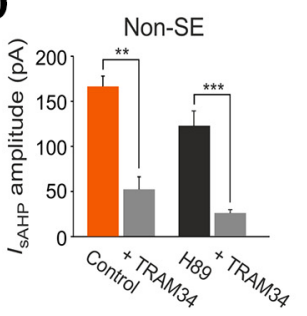

C
B
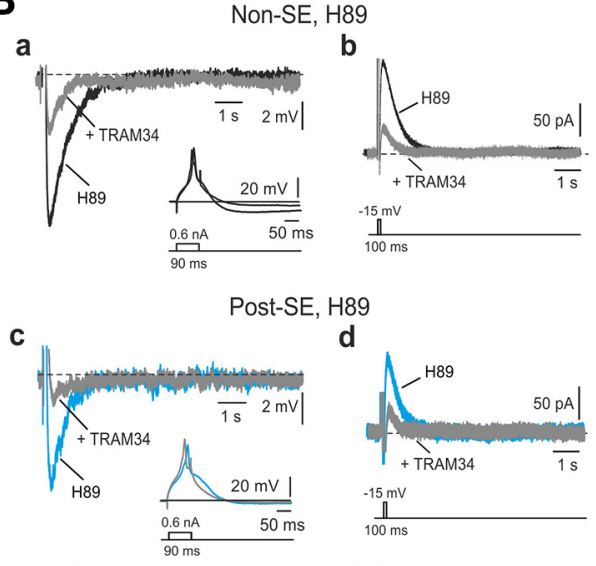

E

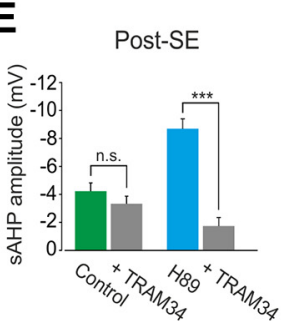

d

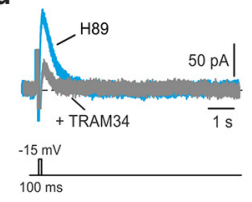

F

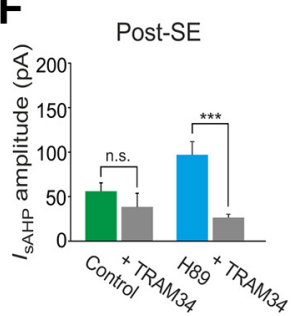

Figure 7. TRAM34 suppresses the native and restored $\mathrm{K}_{\mathrm{Ca}^{2}}$-SAHP and $I_{\text {SAHP }}$ in chronic-phase non-SE and post-SE neurons. Aa, $\boldsymbol{b}$, Representative recordings of $\mathrm{K}_{\mathrm{Ca}}$-SAHPs evoked by $\mathrm{Ca}^{2+}{ }^{2+}$ spikes (shown overlaid in inset; $\boldsymbol{a}$ ) and $I_{\text {sAHP }}$ values evoked by depolarizing pulses $(\boldsymbol{b})$ in a non-SE neuron before (Control) and after the addition of $5 \mu \mathrm{M}$ TRAM34 to the aCSF. $\boldsymbol{c}, \boldsymbol{d}$, Likewise, in a post-SE neuron. $\boldsymbol{B}$, Same as in $\boldsymbol{A}$, but recordings were made in slices treated with the PKA inhibitor H89. Note that in this condition TRAM34 also strongly suppresses the $K_{C_{a}}$-SAHP and $I_{\text {sAHP }}$ in the post-SE neuron. C, Summary bar diagram of $\mathrm{K}_{\mathrm{Ca}}$-SAHP amplitudes in non-SE neurons before (Control) and after the addition of TRAM34 to the aCSF. D, Summary bar diagram of $I_{\text {sAHP }}$ amplitudes in non-SE neurons before (Control) and after the addition of TRAM34 to the aCSF. $E$, Same as in C, but for post-SE neurons. $F$, Same as in D, but for post-SE neurons. Note that both $\mathrm{K}_{\mathrm{Ca}}$-SAHPs and $I_{\text {SAHP }}$ S restored by $\mathrm{H} 89$ treatment are sensitive to $\operatorname{TRAM} 34 .{ }^{* *} p \leq 0.01,{ }^{* * *} p \leq 0.001$. n.s., Not significant.

In non-SE neurons, $\mathrm{K}_{\mathrm{Ca}}$-sAHP amplitudes in H89-treated neurons $(-9.6 \pm 1.2 \mathrm{mV} ; n=6)$ were similar to those in untreated neurons $(-9.5 \pm 1.2 \mathrm{mV} ; n=23$; unpaired Student's $t$ test: $t=0.04 ; \mathrm{df}=27$; $p=0.96$; Fig. $6 G$ ). Likewise, $I_{\text {sAHP }}$ amplitudes were not significantly different in the H89-treated subgroup (131.1 $\pm 11.8 \mathrm{pA} ; n=6)$ compared with the untreated subgroup $(166.0 \pm 11.3 \mathrm{pA} ; n=23$; unpaired Student's $t$ test: $t=1.5 ; \mathrm{df}=27 ; p=0.11$; Fig. $6 H$ ). Thus, inhibiting PKA with $\mathrm{H} 89$ by itself had no significant effect on $\mathrm{K}_{\mathrm{Ca}^{-}}$sAHP in non-SE neurons.

As seen with RPcAMP, $\mathrm{K}_{\mathrm{Ca}}$-sAHP amplitudes in $\mathrm{H} 89$-treated post-SE neurons $(-8.7 \pm 0.7 ; n=6$; Fig. $6 \mathrm{Fa})$, were significantly 2.1-fold larger than in untreated post-SE neurons $(-4.2 \pm 0.6$; $n=23$; unpaired Student's $t$ test: $t=3.6$; $\mathrm{df}=27 ;{ }^{\star *} p=0.001$ ) and very slightly and insignificantly smaller in amplitude $(90.4 \%)$ than those in H89-treated non-SE neurons $(-9.6 \pm 1.2 \mathrm{mV} ; n=$ 6; unpaired Student's $t$ test: $t=0.6 ; \mathrm{df}=10 ; p=0.53$; Fig. $6 E a, G)$. Likewise, $I_{\text {SAHP }}$ amplitudes in H89-treated post-SE neurons $(106 \pm 13.50 \mathrm{pA} ; n=6$; Fig. $6 \mathrm{Fb})$ were significantly 1.9 -fold larger than in untreated post-SE neurons $(56.1 \pm 9.3 ; n=23$; unpaired Student's $t$ test: $t=2.5 ; \mathrm{df}=27 ;{ }^{\star} p=0.02$; Fig. $6 \mathrm{Bb}$ ) and slightly and insignificantly smaller in amplitude $(81.3 \%)$ than in H89-treated non-SE neurons $(131.1 \pm 11.8 \mathrm{pA} ; n=6$; unpaired Student's $t$ test: $t=1.4 ; \mathrm{df}=10 ; p=0.20$; Fig. $6 E b, H)$.

Treating non-SE neurons with $\mathrm{H} 89$ did not affect $\mathrm{Ca}^{2+}$-spike rheobase currents (from $0.48 \pm 0.04$ to $0.43 \pm 0.06 \mathrm{nA}$; unpaired Student's $t$ test: $t=0.6 ; \mathrm{df}=27 ; p=0.53$ ) and amplitudes (from $63.1 \pm 2.2$ to $62.3 \pm 3.7 \mathrm{mV}$; unpaired Student's $t$ test: $t=0.2$; $\mathrm{df}=27 ; p=0.86$ ). Similarly, in post-SE neurons, H89 treatment did not affect $\mathrm{Ca}^{2+}$-spike rheobase currents (from $0.48 \pm 0.04$ to $0.62 \pm 0.05 \mathrm{nA}$; unpaired Student's $t$ test: $t=1.7$; df $=27 ; p=$ 0.07 ) and amplitudes (from $63.4 \pm 2.8$ to $53.9 \pm 3.4 \mathrm{mV}$; un- paired Student's $t$ test: $t=1.6$; $\mathrm{df}=27 ; p=0.12$ ). Thus, inhibiting PKA with $\mathrm{H} 89$ restores $\mathrm{K}_{\mathrm{Ca}}$-sAHP and its underlying current to almost normal values.

Together, these findings suggest that persistent PKA activation underlies $\mathrm{K}_{\mathrm{Ca}}$-sAHP and $I_{\mathrm{sAHP}}$ suppression in chronic-phase post-SE neurons. Therefore, we tested whether restoring $\mathrm{K}_{\mathrm{Ca}}-\mathrm{sAHP}$ with $\mathrm{H} 89$ will also reverse the increase in spike output of chronicphase post-SE neurons. These experiments were conducted in standard aCSF containing $10 \mu \mathrm{M} \mathrm{H} 89$. Spikes were evoked in non-SE and post-SE H89-treated neurons using 1-s-long positive current pulses, as described above (Fig. 1A). As seen in the Ns/I plots (Fig. 6I), post-SE neurons $(n=10$; one additional neuron was excluded as an outlier, because increasing $I$ caused a decrease in Ns and associated sAHP) tended to generate slightly more spikes than non-SE neurons $(n=12)$, but the difference in spike response gain values was not significant $(47.6 \pm 5.0$ and $43.9 \pm 3.9 \mathrm{Ns} / \mathrm{I}$, respectively; MannWhitney test, $p=0.75$; compare Fig. $1 B$ ). Thus, restoring the $\mathrm{K}_{\mathrm{Ca}^{-}}$sAHP in post-SE neurons by inhibiting PKA largely reverses the increase in their excitability.

\section{TRAM34 differentially affects $\mathrm{K}_{\mathrm{Ca}}$-sAHP and $I_{\text {sAHP }}$ in non-SE and post-SE neurons}

We next tested the effects of TRAM34 $(5 \mu \mathrm{M})$ on the isolated $\mathrm{K}_{\mathrm{Ca}}$-sAHP and $I_{\mathrm{sAHP}}$ in chronic-phase neurons. In non-SE neurons $(n=9)$, TRAM34 markedly and significantly decreased $\mathrm{K}_{\mathrm{Ca}^{-}}$ sAHP amplitudes (to $56.2 \%$ of control; from $-9.5 \pm 1.2$ to $-5.3 \pm 0.7 \mathrm{mV}$; paired Student's $t$ test: $t=2.6 ; \mathrm{df}=8 ;{ }^{\star *} p=$ 0.004 ; Fig. $7 A a, C$ ) and $I_{\text {sAHP }}$ amplitudes (to $31.5 \%$ of control; from $166.4 \pm 11.3$ to $52.4 \pm 13.8 \mathrm{pA}$; paired Student's $t$ test, $t=$ 5.0; $\mathrm{df}=8 ;{ }^{* *} p=0.004$; Fig. $\left.7 A b, D\right)$. In contrast, in post-SE neurons $(n=8)$, TRAM34 affected neither $\mathrm{K}_{\mathrm{Ca}}$-sAHP ampli- 
tudes (from $-4.2 \pm 0.6$ to $-3.3 \pm 0.5 \mathrm{mV}$; paired Student's $t$ test: $t=0.8$; df $=7 ; p=0.27$; Fig. $7 A c, E$ ) nor $I_{\text {sAHP }}$ amplitudes (from $56.1 \pm 9.3$ to $38.6 \pm 15.3 \mathrm{pA}$; paired Student's $t$ test: $t=0.1 ; \mathrm{df}=$ $7 ; p=0.35$; Fig. $7 A d, F)$.

In non-SE neurons, TRAM34 had no effects on $\mathrm{Ca}^{2+}$ spike rheobase currents (from $0.48 \pm 0.04$ to $0.51 \pm 0.04 \mathrm{nA}$; paired Student's $t$ test: $t=0.5$; df $=8 ; p=0.60$ ) and amplitudes (from $63.1 \pm 2.2$ to $66.5 \pm 1.7 \mathrm{mV}$; paired Student's $t$ test: $t=1.2 ; \mathrm{df}=$ $8 ; p=0.23)$. In post-SE subgroups, TRAM34 also had no effects on $\mathrm{Ca}^{2+}$ spike rheobase currents (from $0.58 \pm 0.05$ to $0.54 \pm 0.05$ $\mathrm{nA}$; paired Student's $t$ test: $t=0.6 ; \mathrm{df}=7 ; p=0.52)$ and amplitudes (from $63.1 \pm 2.2$ to $66.5 \pm 1.7 \mathrm{mV}$; paired Student's $t$ test: $t=1.2 ; \mathrm{df}=7 ; p=0.10)$.

We similarly tested the effects of TRAM34 on the isolated $\mathrm{K}_{\mathrm{Ca}}$-sAHP and $I_{\text {sAHP }}$ in H89-treated chronic-phase neurons. In H89-treated non-SE neurons $(n=5)$, TRAM34 markedly and significantly decreased $\mathrm{K}_{\mathrm{Ca}}$-sAHP amplitudes (to $30.4 \%$ of control; from $-9.6 \pm 1.2$ to $-2.9 \pm 0.4 \mathrm{mV}$; paired Student's $t$ test: $t=4.8 ; \mathrm{df}=4 ;{ }^{\star * *} p=0.0009$; Fig. $\left.7 \mathrm{Ba}, \mathrm{C}\right)$ and $I_{\text {sAHP }}$ amplitudes (to $23.3 \%$ of control; from $131.1 \pm 11.8$ to $30.5 \pm 6.1 \mathrm{pA}$; paired Student's $t$ test: $t=6.0$; df $=4 ;{ }^{* *} p=0.0001$; Fig. $\left.7 B b, D\right)$. In H89-treated post-SE neurons in which both $\mathrm{K}_{\mathrm{Ca}}$-sAHP and $I_{\mathrm{sAHP}}$ were restored $(n=5)$, TRAM34 also markedly and significantly decreased $\mathrm{K}_{\mathrm{Ca}}$-sAHP amplitudes (to $20.9 \%$ of control; from -8 . $7 \pm 0.7$ to $-1.8 \pm 0.6 \mathrm{mV}$; paired Student's $t$ test: $t=9.3 ; \mathrm{df}=4$; ${ }^{* *} p=0.0001$; Fig. $7 B c, E$ ) and $I_{\mathrm{sAHP}}$ amplitudes (to $29.3 \%$ of control; from $106.7 \pm 13.5$ to $31.3 \pm 4.5 \mathrm{pA}$; paired Student's $t$ test: $t=5.3 ; \mathrm{df}=4 ;{ }^{* *} p=0.0007$; Fig. $\left.7 B d, F\right)$.

In H89-treated non-SE neurons, TRAM34 had no effects on $\mathrm{Ca}^{2+}$ spike rheobase currents (from $0.43 \pm 0.06$ to $0.55 \pm 0.09$ $\mathrm{nA} ; n=5$; paired Student's $t$ test, $t=1.9 ; \mathrm{df}=4 ; p=0.30)$ and amplitudes in (from $62.3 \pm 3.7$ to $71.0 \pm 3.6 \mathrm{mV}$; paired Student's $t$ test: $t=2.7$; $\mathrm{df}=4 ; p=0.13$ ). Likewise, in H89-treated post-SE neurons, TRAM34 had no effects on $\mathrm{Ca}^{2+}$ rheobase currents (from $0.62 \pm 0.05$ to $0.57 \pm 0.03 \mathrm{nA}$; paired Student's $t$ test: $t=0.9 ; \mathrm{df}=4 ; p=0.43$ ) and amplitudes in (from $53.9 \pm 3.4$ to $62.1 \pm 1.3 \mathrm{mV}$; paired Student's $t$ test: $t=1.5 ; \mathrm{df}=4 ; p=0.05$ ).

These results confirm that $\mathrm{K}_{\mathrm{Ca}}-\mathrm{sAHP}$ and $I_{\mathrm{sAHP}}$ in rat CA1 pyramidal cells are generated largely by KCa3.1 channels. Their marked reduction in chronic-phase post-SE neurons is due mainly to PKA-mediated downregulation of KCa3.1 channels and is acutely reversible by PKA inhibition. The identity of the channels generating the residual TRAM34 insensitive $\mathrm{K}_{\mathrm{Ca}}$-sAHP and $I_{\text {sAHP }}$ has yet to be determined.

\section{TRAM34 differentially affects spike output in non-SE and post-SE neurons}

Finally, we examined the effects of TRAM34 on spike output in chronic-phase neurons in standard aCSF. Spikes and sAHPs were evoked using 1-s-long positive current pulses, as described above (Fig. 1A). The firing responses evoked by $0.3 \mathrm{nA}$ pulses in a representative non-SE neuron before and after application of TRAM34 are shown in Figure 8A. TRAM34 caused a marked increase in spike output in all cases $(n=6$; Fig. $8 A a, b)$. As evident from the Ns/I plots (Fig. $8 B a$ ), TRAM34 caused a significant increase in spike response gain values (from $32.0 \pm 3.6$ to $51.4 \pm 7.4$ Ns/I; Wilcoxon signed rank test, $\left.{ }^{*} p=0.04\right)$.

The TRAM34-induced enhanced spike output was associated with sAHP reduction (Fig. $8 A c$ ), consistent with the notion that the increase in spike output is secondary to $\mathrm{K}_{\mathrm{Ca}}$-sAHP inhibition by TRAM34. Congruently, analyses of the TRAM34-induced sAHP reduction indicated that the early sAHP/Ns ratio was significantly reduced (from $0.32 \pm 0.07$ to $0.11 \pm 0.01$; Wilcoxon signed rank test, ${ }^{\star} p=0.02 \mathrm{mV} / \mathrm{Ns}$; Fig. $\left.8 \mathrm{Bb}\right)$, whereas the late $\mathrm{sAHP} / \mathrm{Ns}$ ratio was not (from $0.06 \pm 0.01$ to $0.05 \pm 0.01 \mathrm{mV} / \mathrm{Ns}$; Wilcoxon signed rank test, $p=0.34$; Fig. $8 B c$ ).

We next tested whether TRAM34-induced enhancement of spike output is occluded in post-SE neurons $(n=8)$. As shown in a representative recording from such a neuron, adding TRAM34 did not noticeably affect spike output (Fig. $8 C a, b$ ). Indeed, analyses of the $N$ s/I plots indicated that spike response gain values were not affected by TRAM34 in these neurons (from $64.3 \pm 10.7$ to $64.0 \pm 7.2 \mathrm{Ns} / \mathrm{I}$; Mann-Whitney test, $p=0.82$; Fig. $8 \mathrm{Da}$ ). Likewise, the small sAHPs in post-SE neurons were not further reduced by TRAM34 (Fig. 8Cc), as evident from analyses of early sAHP/Ns ratios (from $0.15 \pm 0.04$ to $0.11 \pm 0.05 \mathrm{mV} / \mathrm{Ns}$; MannWhitney test, $p=0.28$; Fig. $8 D b)$ and late sAHP/Ns ratios $(0.07 \pm$ 0.02 to $0.07 \pm 0.03 \mathrm{mV} / \mathrm{Ns}$; Mann-Whitney test, $p=0.28$; Fig. $8 D c$ ).

These data show that the effects of TRAM34 are occluded in chronic-phase post-SE neurons, as expected if this drug targets $\mathrm{KCa} 3.1$ channels that are already downregulated. Congruently, TRAM34-treated non-SE neurons $(n=6)$ and TRAM34untreated post-SE neurons $(n=8)$, manifested similar spike response gain values $(51.4 \pm 7.4$ and $64.3 \pm 10.7 \mathrm{Ns} / \mathrm{I}$, respectively; Mann-Whitney test, $p=0.91$; Fig. $8 E a$ ). They were also alike in early sAHP/Ns $(0.11 \pm 0.01$ and $0.15 \pm 0.04 \mathrm{mV} / \mathrm{Ns}$, respectively; Mann-Whitney test, $p=0.07$; Fig. $8 E b)$ and late $s A H P / N s$ ratios $(0.05 \pm 0.01$ to $0.07 \pm 0.02 \mathrm{mV} / \mathrm{Ns}$, respectively; Mann-Whitney test, $p=0.53$; Fig. $8 E c)$.

\section{Discussion}

In the present study, we show that the sAHP, a key determinant of neuronal spike output, is strongly reduced in chronic-phase post-SE (i.e., epileptic) CA1 pyramidal cells, causing these neurons to fire more spikes in response to an excitatory stimulus. The sAHP reduction is due to a selective decrease in the $\mathrm{K}_{\mathrm{Ca}}-\mathrm{sAHP}$ component and its underlying current $I_{\mathrm{sAHP}}$, whereas the NKAsAHP component is resilient to the epileptogenic process. Given that $I_{\text {sAHP }}$ is largely mediated by KCa3.1 channels, our study suggests that these channels are downregulated in the epileptic neurons. This effect likely is due to enhanced PKA activity, as PKA inhibition restores $I_{\text {sAHP }}$ to near non-SE levels. The $\mathrm{K}_{\mathrm{Ca}}$-sAHP reduction and resultant increase in spike output of principal neurons, may contribute to the emergence of the chronic epileptic condition in post-SE rats.

\section{Potential mechanisms underlying KCa3.1 downregulation in epileptogenesis}

Multiple mechanisms are implicated in $I_{\mathrm{sAHP}}$ generation and regulation, and aberration of any one of them may contribute to its persistent downregulation in epileptic neurons. Because PKA activation inhibits $I_{\mathrm{sAHP}}$ (Madison and Nicoll, 1986; Pedarzani and Storm, 1993; Haug and Storm, 2000), but fails to modify NKA transport activity in CA1 pyramidal cells (Mohan et al., 2019), we explored its possible involvement in this phenomenon. Intriguingly, the PKA inhibitors H89 and RPcAMP restored most of the TRAM34-sensitive $I_{\text {sAHP }}$ that was downregulated in epileptic neurons. These drugs did not modify $I_{\text {sAHP }}$ in non-SE slices. Therefore, we conclude that $I_{\text {sAHP }}$ is downregulated in the epileptic neurons consequent to enhanced PKA activity.

The KCa3.1 channel is ubiquitously expressed in the plasma membrane of neural and non-neural cells (Wulff and Castle, 2010; Turner et al., 2015). It is voltage independent and is exclusively gated by the binding of intracellular $\mathrm{Ca}^{2+}$ to calmodulin, a $\mathrm{Ca}^{2+}$-binding protein tethered tightly to the proximal $\mathrm{C}$ termi- 
A

Non-SE

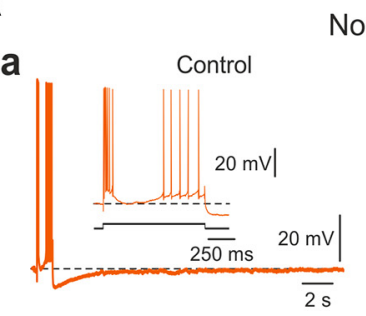

b

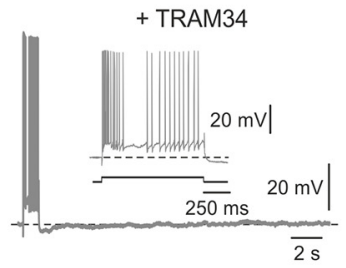

B

a

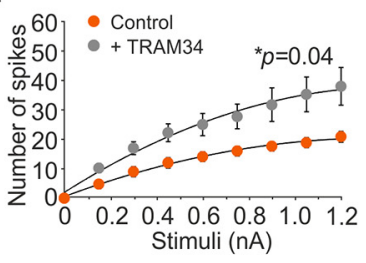

b

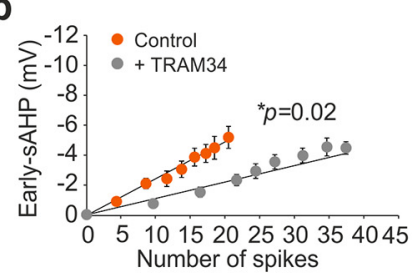

C

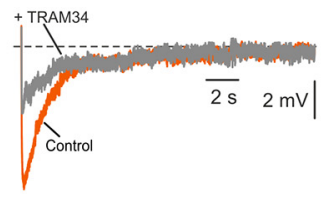

C

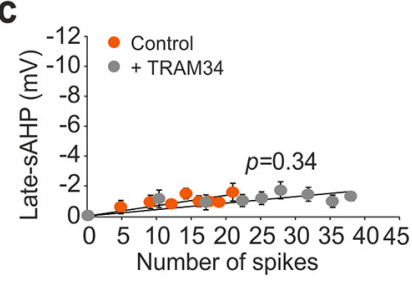

C

a

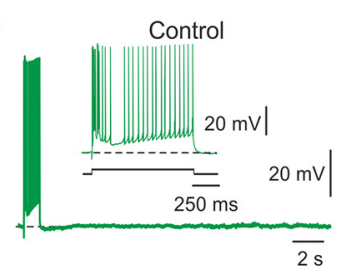

D

a

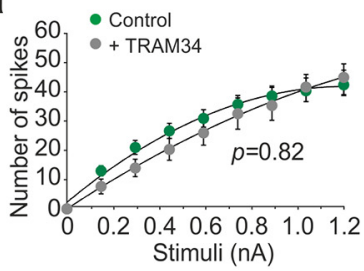

E

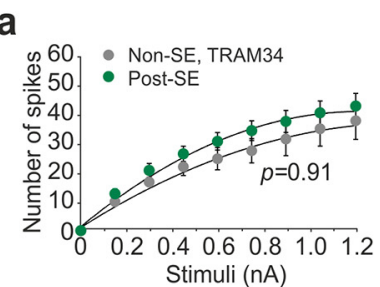

Post-SE

b

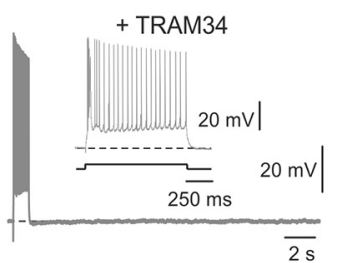

b

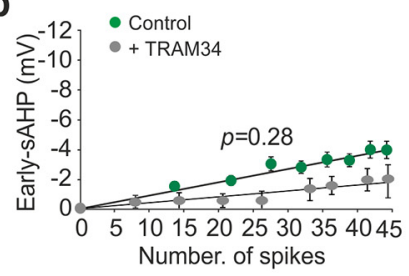

b

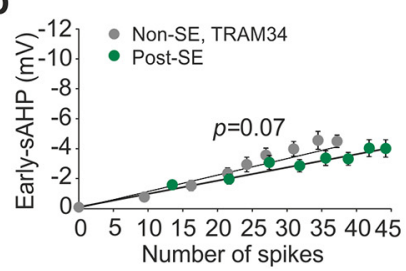

C

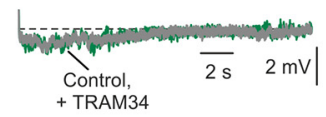

C

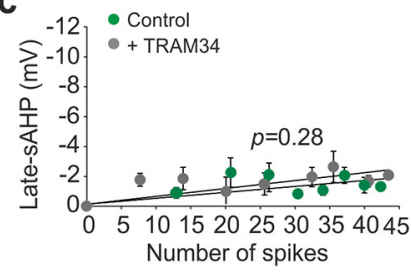

C

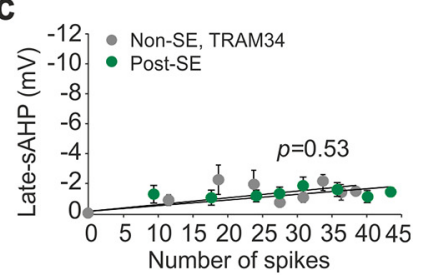

Figure 8. TRAM34 differentially affects spike outputs and SAHPs in chronic-phase non-SE and post-SE neurons. A, Spikes were evoked in a non-SE neuron by 1-s-long depolarizing current pulses from resting $V_{\mathrm{m}}$ of $-70 \mathrm{mV} . \boldsymbol{a}, \boldsymbol{b}$, Representative recordings of spike responses and subsequent sAHPs evoked by $0.3 \mathrm{nA}$ stimuli in the same neuron in standard aCSF before $(\boldsymbol{a})$ and after $(\boldsymbol{b})$ the addition of $5 \mu \mathrm{M}$ TRAM34. The insets depict the spike responses in an enlarged format. The sAHPs evoked in the two conditions are enlarged and overlaid in c. Note the increased spike output and reduced SAHP in TRAM34. Ba, Summary plots of number of spikes versus stimulus intensity for non-SE neurons before (Control) and after TRAM34 application. Note that TRAM34 significantly increases spike output in these neurons. $\boldsymbol{b}$, Summary plots of early sAHP amplitudes (measured at time point $1 \mathrm{~s}$ after the stimulus) versus the number of spikes evoked in non-SE neurons before (Control) and after TRAM34 application. $\boldsymbol{c}$, Same as in $\boldsymbol{b}$, but for late sAHP amplitudes (measured at time point $7 \mathrm{~s}$ after the stimulus). Note that in these non-SE neurons, TRAM34 significantly suppresses the early sAHPs but not the late SAHPs. $\boldsymbol{C}$, Same as in $\boldsymbol{A}$, but for post-SE neurons. $\boldsymbol{D}$, Same as in $\boldsymbol{B}$, but for post-SE neurons. Note that in post-SE neurons, TRAM34 has no significant effects on spike outputs and SAHPs. Ea, Comparison of summary plots of number of spikes versus stimulus intensity between TRAM34-treated non-SE neurons and untreated post-SE neurons. $\boldsymbol{b}$, Same as in $\boldsymbol{a}$, but for summary plots of early sAHP amplitudes versus the number of spikes. $\boldsymbol{c}$, Same as in $\boldsymbol{a}$, but for summary plots of late sAHP amplitudes versus the number of spikes. Note that TRAM34-treated non-SE neurons are similar to post-SE neurons with respect to spike output and SAHP size.

nus of KCa3.1 channel $\alpha$ subunit (Fanger et al., 1999; Khanna et al., 1999; Morales et al., 2013). Studies in non-neural tissues and in expression systems have demonstrated inhibition of KCa3.1 activity by PKA-mediated phosphorylation at sites located at the calmodulin-binding region of the channel (Neylon et al., 2004; Choi et al., 2012; Wong and Schlichter, 2014).

The $I_{\mathrm{sAHP}}$ reduction by PKA-mediated phosphorylation is normally reversed by serine/threonine phosphatases (PPs), such as PP-1, PP-2A, and/or PP-2B (Pedarzani et al., 1998; Vogalis et al., 2004). Inhibition of these PPs also would reduce $I_{\text {sAHP }}$ by augmenting the effect of ongoing PKA-mediated KCa3.1 phosphorylation. Our finding that PKA inhibitors restore $I_{\mathrm{sAHP}}$ is more congruent with increased PKA activity than with decreased PP activity as the main mechanism of $I_{\mathrm{sAHP}}$ reduction in epileptic neurons. In either case, however, PKA activity is the main cause of KCa3.1 downregulation in the epileptic neurons. 
What may cause a sustained increase in PKA activity in epileptic neurons? Multiple primary messengers converge via G-protein-coupled receptors (GPCRs) and the PKA signaling pathway to suppress $I_{\text {sAHP }}$ (Madison and Nicoll, 1986; Pedarzani and Storm, 1993; Haug and Storm, 2000). Upregulation of one or more of these messengers and/or receptors following pilocarpineinduced SE would persistently enhance KCa3.1 phosphorylation, leading to $I_{\text {sAHP }}$ reduction in epileptic neurons. For example, it was shown that pilocarpine-SE induces a sustained increase in the tonic activity of mesolimbic dopaminergic neurons (Cifelli and Grace, 2012), some of which also project to CA1 (Verney et al., 1985). Enhanced release of dopamine onto CA1 pyramidal cells likely would cause $I_{\text {sAHP }}$ suppression via PKA activation (Pedarzani and Storm, 1995).

Further studies with selective GPCRs antagonists are required to identify primary messengers whose enhanced activity in epileptic tissue may induce $I_{\mathrm{sAHP}}$ suppression in principal neurons.

\section{KCa3.1 downregulation and enhanced neuronal firing in epileptogenesis}

As previously described, the spike output of chronic-phase post-SE neurons was increased compared with chronic-phase non-SE neurons or early-phase post-SE neurons (the two latter groups manifested similar spike outputs). This increase in firing was associated with a decrease in the early sAHP and likely is the consequence of the reduced negative feedback normally provided by $\mathrm{K}_{\mathrm{Ca}}$-sAHP.

Numerous studies have shown previously that blocking $\mathrm{K}_{\mathrm{Ca}^{-}}$ sAHP enhances spike output in normal CA1 pyramidal cells (Madison and Nicoll, 1984; Lancaster and Nicoll, 1987; Pedarzani and Storm, 1993, 1995; King et al., 2015). The question then arises of whether $\mathrm{K}_{\mathrm{Ca}}$-sAHP suppression is the main mechanism responsible for the increased spike output in epileptic CA1 pyramidal cells (Tamir et al., 2017). Three findings are pertinent to this question. First, the spike output of chronic-phase non-SE neurons or early-phase post-SE neurons treated with TRAM34 to block $\mathrm{K}_{\mathrm{Ca}}$-sAHP was quantitatively similar to that of the epileptic neurons. Second, the facilitation of spike output by TRAM34 was occluded in the epileptic neurons. Third, restoring $\mathrm{K}_{\mathrm{Ca}}$-sAHP in epileptic neurons by inhibiting PKA activity decreased spike output back to near non-SE values. Altogether, these results strongly suggest that $\mathrm{K}_{\mathrm{Ca}}-\mathrm{sAHP}$ reduction in epileptic neurons is the predominant mechanism underlying the increase in spike output.

\section{Constancy of the NKA-sAHP in epileptogenesis}

Unlike the $\mathrm{K}_{\mathrm{Ca}}$-sAHP component, the NKA-sAHP component did not change in post-SE neurons, suggesting that neuronal NKA activity is resilient to the epileptogenic process. Former studies of NKA transport activity, using biochemical methodology in homogenized hippocampal tissue from pilocarpinetreated animals, reported either an increase (rats; Fernandes et al., 1996) or a decrease (mice; Funck et al., 2014) in chronic-phase post-SE rat tissue. Whatever the reason for the discrepant results, these studies do not provide insight into specific changes in neuronal NKAs, as homogenized tissue comprises multiple cell types. Our observations of NKA activity in single identified neurons suggest that major alterations in neuronal NKA transport activity do not occur in pilocarpine-SE-induced epileptogenesis.

Notwithstanding, the selective decrease in $\mathrm{K}_{\mathrm{Ca}}$-sAHP in epileptic neurons and the resultant increase in their excitability imply that NKAs are bestowed a critical role in controlling the excitability of epileptic tissue (i.e., transient reductions in NKA activity would be more likely to provoke seizures in neuronal tissue lacking functional KCa3.1 channels than in tissue containing operative channels). Given that the transport activity of neuronal NKAs is also continuously regulated by phosphorylation/ dephosphorylation (Mohan et al., 2019), as well as by ATP availability (Erecińska and Dagani, 1990), endogenous "cardiotonic" steroids (Bagrov et al., 2009), and numerous other factors (Therien and Blostein, 2000), it is conceivable that even physiological fluctuations in NKA activity that normally are innocuous may provoke seizures in epileptic brain.

\section{Concluding remarks}

Epileptogenesis induced by SE is associated with multiple translational and post-translation modifications of gene expression (Pitkänen et al., 2015). The epileptic condition likely results from several alterations in synaptic and neuronal functions, conjointly perturbing the delicate excitation/inhibition balance that normally prevents the outbreak of seizures. Previous studies of the pilocarpine-SE model have disclosed several acquired channelopathies that may contribute to epileptogenesis and/or to the maintenance of the epileptic condition-upregulation of T-type voltage-gated $\mathrm{Ca}^{2+}$ channels (Su et al., 2002; Yaari et al., 2007; Becker et al., 2008) and of persistent $\mathrm{Na}^{+}$channels (Chen et al., 2011; Royeck et al., 2015), as well as the downregulation of dendritic A-type $\mathrm{K}^{+}$channels (Bernard et al., 2004) and of HCN channels (Jung et al., 2007, 2010). The design of new antiepileptogenic and antiepileptic treatments based on these putative drug targets is beginning to yield encouraging results (Doeser et al., 2015; van Loo et al., 2015). The novel acquired channelopathy described here, namely, the almost complete downregulation of KCa3.1 activity, provides another innovative and promising target for developing new treatments for TLE, hopefully overcoming the pharmacoresistance to traditional drugs.

\section{References}

Bagrov AY, Shapiro JI, Fedorova OV (2009) Endogenous cardiotonic steroids: physiology, pharmacology, and novel therapeutic targets. Pharmacol Rev 61:9-38.

Becker AJ (2018) Review: animal models of acquired epilepsy: insights into mechanisms of human epileptogenesis. Neuropathol Appl Neurobiol 44: 112-129.

Becker AJ, Pitsch J, Sochivko D, Opitz T, Staniek M, Chen CC, Campbell KP, Schoch S, Yaari Y, Beck H (2008) Transcriptional upregulation of $\mathrm{Ca}_{\mathrm{v}} 3.2$ mediates epileptogenesis in the pilocarpine model of epilepsy. J Neurosci 28:13341-13353.

Bernard C, Anderson A, Becker A, Poolos NP, Beck H, Johnston D (2004) Acquired dendritic channelopathy in temporal lobe epilepsy. Science 305: $532-535$.

Chen S, Su H, Yue C, Remy S, Royeck M, Sochivko D, Opitz T, Beck H, Yaari Y (2011) An increase in persistent sodium current contributes to intrinsic neuronal bursting after status epilepticus. J Neurophysiol 105:117129.

Chijiwa T, Mishima A. Hagiwara M, Sano M, Hayashi K, Inoue T, Naito K, Toshioka T, Hidaka H (1990) Inhibition of forskolin-induced neurite outgrowth and protein phosphorylation by a newly synthesized selective inhibitor of cyclic AMP-dependent protein kinase, $\mathrm{N}$-[2-(p-bromocinnamylamino)ethyl]-5-isoquinolinesulfonamide (H89), of PC12D pheochro-mocytoma cells. J Biol Chem 265:5267-5272.

Choi S, Kim MY, Joo KY, Park S, Kim JA, Jung JC, Oh S, Suh SH (2012) Modafinil inhibits K Ca3.1 currents and muscle contraction via a cAMPdependent mechanism. Pharmacol Res 66:51-59.

Cifelli P, Grace AA (2012) Pilocarpine-induced temporal lobe epilepsy in the rat is associated with increased dopamine neuron activity. Int J Neuropsychopharmacol 15:957-964.

Doeser A, Dickhof G, Reitze M, Uebachs M, Schaub C, Pires NM, Bonifácio MJ, Soares-da-Silva P, Beck H (2015) Targeting pharmacoresistant epilepsy and epileptogenesis with a dual-purpose antiepileptic drug. Brain 138:371-387. 
Dostmann WR, Taylor SS, Genieser HG, Jastorff B, Døskeland SO, Ogreid D (1990) Probing the cyclic nucleotide binding sites of cAMP-dependent protein kinases I and II with analogs of adenosine $3^{\prime}, 5^{\prime}$-cyclic phosphorothioates. J Biol Chem 265:10484-10491.

Erecińska M, Dagani F (1990) Relationships between the neuronal sodium/ potassium pump and energy metabolism. effects of $\mathrm{K}^{+}, \mathrm{Na}^{+}$, and adenosine triphosphate in isolated brain synaptosomes. J Gen Physiol 95:591-616.

Fanger CM, Ghanshani S, Logsdon NJ, Rauer H, Kalman K, Zhou J, Beckingham K, Chandy KG, Cahalan MD, Aiyar J (1999) Calmodulin mediates calcium-dependent activation of the intermediate conductance $\mathrm{KCa}$ channel, IKCal. J Biol Chem 274:5746-5754.

Fernandes MJ, Naffah-Mazzacoratti MG, Cavalheiro EA (1996) $\mathrm{Na}^{+} \mathrm{K}^{+}$ ATPase activity in the rat hippocampus: a study in the pilocarpine model of epilepsy. Neurochem Int 28:497-500.

Funck VR, Ribeiro LR, Pereira LM, de Oliveira CV, Grigoletto J, Fighera MR, Royes LF, Furian AF, Oliveira MS (2014) Long-term decrease in $\mathrm{Na}^{+}$, $\mathrm{K}^{+}$-ATPase activity after pilocarpine-induced status epilepticus is associated with nitration of its alpha subunit. Epilepsy Res 108:1705-1710.

Gulledge AT, Dasari S, Onoue K, Stephens EK, Hasse JM, Avesar D (2013) A sodium-pump-mediated afterhyperpolarization in pyramidal neurons. J Neurosci 33:13025-13041.

Ha GE, Cheong E (2017) Spike frequency adaptation in neurons of the central nervous system. Exp Neurobiol 26:179-185.

Haug T, Storm JF (2000) Protein kinase A mediates the modulation of the slow $\mathrm{Ca}^{2+}$-dependent $\mathrm{K}^{+}$current, I(sAHP), by the neuropeptides CRF, VIP, and CGRP in hippocampal pyramidal neurons. J Neurophysiol 83:2071-2079.

Jung S, Jones TD, Lugo JN Jr, Sheerin AH, Miller JW, D'Ambrosio R, Anderson AE, Poolos NP (2007) Progressive dendritic HCN channelopathy during epileptogenesis in the rat pilocarpine model of epilepsy. J Neurosci 27:13012-13021.

Jung S, Bullis JB, Lau IH, Jones TD, Warner LN, Poolos NP (2010) Downregulation of dendritic $\mathrm{HCN}$ channel gating in epilepsy is mediated by altered phosphorylation signaling. J Neurosci 30:6678-6688.

Khanna R, Chang MC, Joiner WJ, Kaczmarek LK, Schlichter LC (1999) hSK4/hIK1, a calmodulin-binding KCa channel in human T lymphocytes. roles in proliferation and volume regulation. J Biol Chem 274:14838-14849.

King B, Rizwan AP, Asmara H, Heath NC, Engbers JD, Dykstra S, Bartoletti TM, Hameed S, Zamponi GW, Turner RW (2015) IKCa channels are a critical determinant of the slow AHP in CA1 pyramidal neurons. Cell Rep 11:175-182.

Kwan P, Schachter SC, Brodie MJ (2011) Drug-resistant epilepsy. N Engl J Med 365:919-926.

Lancaster B, Nicoll RA (1987) Properties of two calcium-activated hyperpolarizations in rat hippocampal neurones. J Physiol 389:187-203.

Madison DV, Nicoll RA (1984) Control of the repetitive discharge of rat CA 1 pyramidal neurones in vitro. J Physiol 354:319-331.

Madison DV, Nicoll RA (1986) Actions of noradrenaline recorded intracellularly in rat hippocampal CA1 pyramidal neurones, in vitro. J Physiol 372:221-244.

Mohan S, Tiwari NM, Biala Y, Yaari Y (2019) Regulation of neuronal $\mathrm{Na}^{+} /$ $\mathrm{K}^{+}$-ATPase by specific protein kinases and protein phosphatases. J Neurosci 39:5440-5451.

Morales P, Garneau L, Klein H, Lavoie MF, Parent L, Sauvé R (2013) Contribution of the KCa3.1 channel-calmodulin interactions to the regulation of the KCa3.1 gating process. J Gen Physiol 142:37-60.

Neylon CB, D'Souza T, Reinhart PH (2004) Protein kinase A inhibits intermediate conductance $\mathrm{Ca}^{2+}$-activated $\mathrm{K}^{+}$channels expressed in Xenopus oocytes. Pflugers Arch 448:613-620.

Pedarzani P, Storm JF (1993) Pka mediates the effects of monoamine transmitters on the $\mathrm{K}^{+}$current underlying the slow spike frequency adaptation in hippocampal neurons. Neuron 11:1023-1035.

Pedarzani P, Storm JF (1995) Dopamine modulates the slow $\mathrm{Ca}^{2+}$ activated $\mathrm{K}^{+}$current IAHP via cyclic AMP-dependent protein kinase in hippocampal neurons. J Neurophysiol 74:2749-2753.

Pedarzani P, Krause M, Haug T, Storm JF, Stühmer W (1998) Modulation of the $\mathrm{Ca}^{2+}$-activated $\mathrm{K}^{+}$current sIAHP by a phosphatase-kinase balance under basal conditions in rat CA1 pyramidal neurons. J Neurophysiol 79:3252-3256.
Pitkänen A, Lukasiuk K, Dudek FE, Staley KJ (2015) Epileptogenesis. Cold Spring Harb Perspect Med 5:a022822.

Raol YH, Brooks-Kayal AR (2012) Experimental models of seizures and epilepsies. Prog Mol Biol Transl Sci 105:57-82.

Royeck M, Kelly T, Opitz T, Otte DM, Rennhack A, Woitecki A, Pitsch J, Becker A, Schoch S, Kaupp UB, Yaari Y, Zimmer A, Beck H (2015) Downregulation of spermine augments dendritic persistent sodium currents and synaptic integration after status epilepticus. J Neurosci 35:15240-15253.

Sahu G, Asmara H, Zhang FX, Zamponi GW, Turner RW (2017) Activitydependent facilitation of $\mathrm{Ca}_{\mathrm{V}} 1.3$ calcium channels promotes KCa3.1 activation in hippocampal neurons. J Neurosci 37:11255-11270.

Sanabria ER, Su H, Yaari Y (2001) Initiation of network bursts by Ca2+dependent intrinsic bursting in the rat pilocarpine model of temporal lobe epilepsy. J Physiol 532:205-216.

Scharfman HE, MacLusky NJ (2014) Sex differences in the neurobiology of epilepsy: a preclinical perspective. Neurobiol Dis 72:180-192.

Spencer SS, Spencer DD (1994) Entorhinal-hippocampal interactions in medial temporal lobe epilepsy. Epilepsia 35:721-727.

Storm JF (1989) An after-hyperpolarization of medium duration in rat hippocampal pyramidal cells. J Physiol 409:171-190.

Su H, Sochivko D, Becker A, Chen J, Jiang Y, Yaari Y, Beck H (2002) Upregulation of a T-type $\mathrm{Ca}^{2+}$ channel causes a long-lasting modification of neuronal firing mode after status epilepticus. J Neurosci 22:3645-3655.

Tamir I, Daninos M, Yaari Y (2017) Plasticity of intrinsic firing response gain in principal hippocampal neurons following pilocarpine-induced status epilepticus. Neuroscience 357:325-337.

Téllez-Zenteno JF, Hernández-Ronquillo L (2012) A review of the epidemiology of temporal lobe epilepsy. Epilepsy Res Treat 2012:630853.

Therien AG, Blostein R (2000) Mechanisms of sodium pump regulation. Am J Physiol Cell Physiol 279:C541-C566.

Tiwari MN, Mohan S, Biala Y, Yaari Y (2018) Differential contributions of $\mathrm{Ca}^{2+}$-activated $\mathrm{K}^{+}$channels and $\mathrm{Na}^{+} / \mathrm{K}^{+}$-ATPases to the generation of the slow afterhyperpolarization in CA1 pyramidal cells. Hippocampus 28:338-357.

Turner RW, Kruskic M, Teves M, Scheidl-Yee T, Hameed S, Zamponi GW (2015) Neuronal expression of the intermediate conductance calciumactivated potassium channel KCa3.1 in the mammalian central nervous system. Pflugers Arch 467:311-328.

Turner RW, Asmara H, Engbers JD, Miclat J, Rizwan AP, Sahu G, Zamponi GW (2016) Assessing the role of IKCa channels in generating the sAHP of CA1 hippocampal pyramidal cells. Channels 10:313-319.

Turski WA, Cavalheiro EA, Schwarz M, Czuczwar SJ, Kleinrok Z, Turski L (1983) Limbic seizures produced by pilocarpine in rats: behavioural, electroencephalographic and neuropathological study. Behav Brain Res 9:315-335.

van Loo KM, Schaub C, Pitsch J, Kulbida R, Opitz T, Ekstein D, Dalal A, Urbach H, Beck H, Yaari Y, Schoch S, Becker AJ (2015) Zinc regulates a key transcriptional pathway for epileptogenesis via metal-regulatory transcription factor-1. Nat Commun 6:8688.

Verney C, Baulac M, Berger B, Alvarez C, Vigny A, Helle KB (1985) Morphological evidence for a dopaminergic terminal field in the hippocampal formation of young and adult rat. Neuroscience 14:1039-1052.

Vogalis F, Harvey JR, Furness JB (2004) Suppression of a slow post-spike afterhyperpolarization by calcineurin inhibitors. Eur J Neurosci 19:2650-2658.

Wang LY, Salter MW, MacDonald JF (1991) Regulation of kainate receptors by cAMP-dependent protein kinase and phosphatases. Science 253:11321135.

Wong R, Schlichter LC (2014) PKA reduces the rat and human KCa3.1 current, $\mathrm{CaM}$ binding, and $\mathrm{Ca}^{2+}$ signaling, which requires Ser332/334 in the CaM-binding C terminus. J Neurosci 34:13371-13383.

Wulff H, Castle NA (2010) Therapeutic potential of KCa3.1 blockers: recent advances and promising trends. Expert Rev Clin Pharmacol 3:385-396.

Yaari Y, Yue C, Su H (2007) Recruitment of apical dendritic T-type $\mathrm{Ca}^{2+}$ channels by backpropagating spikes underlies de novo intrinsic bursting in hippocampal epileptogenesis. J Physiol 580:435-450.

Yue C, Yaari Y (2006) Axo-somatic and apical dendritic Kv7/M channels differentially regulate the intrinsic excitability of adult rat CA1 pyramidal cells. J Neurophysiol 95:3480-3495. 